\begin{tabular}{|c|c|c|c|c|c|}
\hline MUNIBE Antropologia-Arkeologia & $n^{\circ} 67$ & $75-103$ & DONOSTIA & 2016 & ISSN 1132-2217 • eISSN 2172-4555 \\
\hline
\end{tabular}

\title{
Muertes ritualizadas en la Edad del Bronce de la Península Ibérica: un enterramiento inusual en Los Rompizales (Quintanadueñas, Burgos)
}

\author{
Ritualized killings in the Iberian Bronze Age: An unusual burial at \\ Los Rompizales (Quintanadueñas, prov. Burgos, Spain)
}

PALABRAS CLAVES: Cogotas I. Bioarqueología. Arqueotanatología. Muerte violenta. Mala muerte. GAKO-HITZAK: Cogotas I. Bioarkeologia. Arkeotanatologia. Indarkeriazko heriotza. Heriotza bortitza. KEY WORDS: Cogotas I. Bioarchaeology. Archaeothanatology. Violent death. Bad death.

\section{Javier VELASCO-VÁZQUEZ ${ }^{(1)}$ y Ángel ESPARZA ARROYO(2)}

\section{RESUMEN}

Se presenta un excepcional caso de muerte de cuatro individuos (tres masculinos y uno femenino, fallecidos entre los 7 y los 17 años) hallados en un enterramiento en hoyo de la fase formativa de Cogotas I, en la Edad del Bronce de la Meseta. El modelo bayesiano de las dataciones radiocarbónicas sitúa el enterramiento entre 1501 y 1431 cal BC. Tras examinar las lesiones óseas identificadas en los cuatro y determinar que fueron el resultado de acciones violentas se discute su correspondencia con varios tipos de violencia interpersonal. Excluida la posibilidad de que fueran el resultado de una confrontación bélica se toman en consideración otras posibilidades (sacrificios, 'muertes de acompañamiento' y ejecuciones), difíciles de distinguir con precisión en ausencia de fuentes escritas u orales. Menos controvertida sería, en cambio, la lectura arqueológica que deriva en el reconocimiento de una fuerte ritualización del conjunto y su conexión con los mecanismos de mantenimiento del orden social.

\section{LABURPENA}

Mesetako Brontze Aroan Cogotas I. aztarnategiko eraketa-fasean, hobian egindako ehorzketa batean topatutako lau banakoren aparteko heriotza kasu bat aurkezten dugu ( 7 eta 17 urteen artean hil ziren, eta hiru gizonezkoenak dira, eta bat emakumezko batena). Datazio erradiokarbonikoen eredu bayestarrak ehorzketa hori K.a. 1501-1431 kalibrazio-urtean kokatu du. Lauretan identifikatutako hezurretako lesioak aztertu eta indarkeriako ekintzen emaitza izan zirela zehaztu ondoren, pertsona arteko indarkeria mota batzuekin duen elkarrekikotasuna eztabaidatu da. Borroka beliko baten emaitza izateko aukera baztertu ondoren, beste aukera batzuk landu dira (sakrifizioak, "laguntzeko heriotzak" eta exekuzioak), baina zaila da idatzizko edo ahozko iturririk gabe horiek zehatz-mehatz bereiztea. Aldiz, multzoaren erritualizazio-iturria izan zela eta ordena soziala mantentzeko mekanismoekin lotura zuela aitortzetik eratorritako irakurketa arkeologikoa ez litzateke horren eztabaidagarria izango.

\section{ABSTRACT}

This paper presents an exceptional case concerning the death of four subadults, found in a pit burial corresponding to the Formative phase of the archaeological culture of Cogotas I, the Middle Bronze Age in the central Plateau of the Iberian Peninsula. The Bayesian model applied to the radiocarbon results dates the burial between Cal BC 1501 and Cal BC 1431. The examination of bone lesions identified in the individuals (three male and one female, died between 7 and 17 years) has allowed to conclude that in all cases they were caused by violent actions, inducing their death. Three of the individuals, those placed in a lateral decubitus position following the perimeter of the pit, suffered traumas caused by violent blows to the head, inflicted from behind with a heavy and blunt shape instrument. On the other hand, the individual who occupied the center of the pit burial, laid in a ventral decubitus position, displays a perimortem incised lesion on his eleventh thoracic vertebra. It must have been caused by the severe impact of a thin, double-edged pointed object, most probably a dagger or a similar weapon.

Taking into account the type and location of the injuries, as well as the particular arrangement of the bodies in the pit, a social analysis about the circumstances of the death and the mortuary behaviours it has been carried out to explain this exceptional case for the Bronze Age of the Iberian Peninsula. After excluding that the injuries were a consequence of a confrontation, other possibilities of social violence are considered, specifically, sacrifice, 'accompanying deaths' and execution, which are hard to accurately distinguish in the archaeological record in the absence of written or oral sources. With all due cautions, we propose that the most likely scenario for Rompizales could be a death penalty case.

\footnotetext{
(1) Departamento de Ciencias Históricas. Universidad de Las Palmas de Gran Canaria. 35003 Las Palmas de Gran Canaria. Tfno.: (+34) 928 458922 / Fax: (+34) 928452722. E-mail: javier.velasco@ulpgc.es

(2) Departamento de Prehistoria, Historia Antigua y Arqueología. Universidad de Salamanca. 37071 Salamanca. Tfno.: (+34) 923294550, fax: (+34)923294737. E-mail: esparza@usal.es
} 
Less controversial would be instead the clear ritualization of the burial and its association with various social mechanisms, among them the violence, deployed to the maintenance of the social order. In this sense, the different and devastating formulas used to kill these individuals and their relationship with the place that each one occupy in the pit, as well as the organization of mortuary space, the deliberate fact of dispose the bodies, the way they were covered... are elements to consider an express will of carrying out a mise-en-scène with the development of a codified and ritualized dramatization around the death and burial of these subadults. In other words, all data suggest that Rompizales is an example of 'ritual culturally sanctioned violence', thus recognizing a new variant of 'bad death' within the funerary practices of Cogotas I.

\section{1.- INTRODUCCIÓN}

La investigación arqueológica acerca de la más antigua violencia ha conocido notables avances, tanto en el terreno de los datos empíricos (p.ej. GUILAINE Y ZAMMIT, 2001) como en la construcción de una metodología y en la reflexión teórica, muy vinculada a la de la antropología (vid. ARMIT et al., 2007; OTTO et al., 2006; RALPH, 2013; SCHMITT Y SCHRÖDER, 2001). Los resultados son espectaculares en un campo, el de la violencia bélica, en el que puede darse una afortunada confluencia de fuentes diversas, como el registro osteoarqueológico, las estructuras defensivas, el armamento o las representaciones iconográficas. En cambio, otros aspectos como el de la violencia no bélica, aplicada principalmente en el interior de la sociedad, o en general las formas de homicidio socialmente aprobado, tienen todavía un menor recorrido, probablemente porque su base osteológica — casi la única- presenta especiales dificultades. No hace mucho PAUKETAT (2009: 260) enfatizaba la comparativamente escasa atención prestada a esas otras formas de matar, "ya sean inmolaciones sacrificiales, ejecuciones de criminales y brujos, o la muerte de miembros de la familia a manos de patriarcas. Ha habido poca reflexión sobre la organización o la transferencia de la violencia en la sociedad y sobre la práctica diaria y la inculcación de las sensibilidades agresivas", y desde entonces las cosas no han cambiado sustancialmente, a excepción de las arqueologías americanas, donde estos temas, especialmente los de los sacrificios humanos y las matanzas de brujos han venido gozando de importante atención, contando con bases etnohistóricas (p.ej., DARLING, 1998; FAUX, 2012; OGILVIE Y HILTON, 2000, TIESLER Y CUCINA, 2007). Ello ha permitido que objetivos como las variaciones históricas en las diferentes formas de violencia y su intensidad sean ya habituales en esas regiones (p. ej., PÉREZ, 2011). La violencia, lejos de ser un hecho aislado, es entendida en relación con prácticas grupales complejas, llegándose a proponer formulaciones teóricas como el 'Modelo de politización de la Muerte', "diseñado para integrar las múltiples variables que pueden afectar a ámbitos de interacción regional, entre ellos factores de estrés, ambientales, políticos y económicos" (ibid.: 137-8).

En el caso de las sociedades prehistóricas europeas, hay bases para suponer que las tensiones internas, entre individuos y entre distintos segmentos sociales, también generaban formas específicas de violencia: además de la individual, de limitado alcance, la ejercida estructuralmente sobre las capas inferiores, la violencia por razón de sexo, y otras como sacrificios y ejecuciones, han debido de jugar un papel muy importante en la constitución y mantenimiento del orden social y por ello merecen ser investigadas. Por estas razones, la distinción de qué forma de violencia puede reconocerse en cada caso debe descansar en una rigurosa metodología bioarqueológica, inspirada en la Antropología Forense (ETXEBERRIA, 2003; MARTIN Y ANDERSON, 2014), como también en la investigación arqueológica centrada en los denominados deviant, o mejor, unusual burials (MURPHY, 2008), sin olvidar la propia imagen que de la sociedad puede ofrecer el registro arqueológico, especialmente armas y estructuras defensivas. Pero se necesita además impulso antropológico e histórico y, hoy todavía, mucha más evidencia empírica, pues es preciso disponer de un amplio corpus de datos que permita desvelar alguna repetición de gestos formalizados ('scripts', sensu GRAMSCH Y MEIER, 2013). Los casos concretos pueden contribuir a documentar formas diversas y establecer su alcance cuantitativo, a explorar posibles patrones y contextos sociales. Desde luego, si aspiramos a comprender los episodios violentos no como acontecimientos extraordinarios sino como indicadores de las dinámicas sociales es imprescindible "que a partir de datos empíricos y modelos teóricos comiencen a clasificarse los tipos específicos de violencia en vez de reducir toda la violencia a una sola categoría homogénea (PÉREZ Y WEISS-KREJCI, 2011:110).

En la Península lbérica se han hallado no pocos testimonios de formas bien distintas de violencia. En unos casos - por ejemplo los de Soto de Tovilla (ESPARZA et al., 2008) o Yeseras y Humanejos (LIESAU et al., 2014 )— parece tratarse de algo de tipo individual, muy limitado, o alguna escaramuza ocasional, como se ha apuntado para hallazgos recientes de Noroeste (SORIANO et al., 2015); pero sobresalen otros, sin duda de mayor alcance cuantitativo y de índole probablemente bélica, como los del Cerro de la Cabeza (FABIÁN Y BLANCO, 2012) y sobre todo el hipogeo de Lóngar (ARMENDARIZ E IRIGARAY, 1994), que contenía un centenar de esqueletos, o el covacho de San Juan ante Portam Latinam, donde fueron enterrados tres centenares de individuos (VEGAS et al., 1999; 2012). También se ha detectado alguno, como el de Los Cercados de Mucientes (GARCÍA BARRIOS, 2007), que vendría a testimoniar la violencia de género, probablemente estructural.

Pero los avances en esta especialidad investigadora parecen darse de forma muy clara en el Neolítico/Megalitismo y Calcolítico, etapas a las que corresponden los yacimientos antes citados, mientras que en nuestra Edad del Bronce son bastante más escasos, casi limitados al ámbito argárico (JIMÉNEZ BROBEIL et al., 2009), donde se debate acerca del alcance de la violencia, 
escasamente detectada todavía en el registro osteológico, y del papel de las armas (ARANDA et al., 2009). La investigación ha saltado, gracias al mismo equipo, a la cultura de Las Motillas (NÁJERA et al., 2010; JIMÉNEZ BROBEIL et al., 2014), pero hay un gran vacío en el resto de las áreas del Bronce de la Península Ibérica. Por eso, como contribución a la necesaria ampliación del corpus de evidencia, aportamos en este trabajo un excepcional caso de violencia detectado en el seno de la "cultura arqueológica" de Cogotas I.

\section{ENCUADRE CRONO-CULTURAL DEL HA- LLAZGO: COGOTAS I}

Entre las entidades arqueológicas de la Edad del Bronce peninsular, Cogotas I sobresale por su extensa cobertura geográfica, que desborda la Meseta por el Valle del Ebro y Extremadura, y por su dilatada cronología - c. 1800-1150 cal BC, cubriendo el Bronce Medio y Tardío de la secuencia regional-, habiendo sido caracterizada en recientes trabajos de síntesis (ABARQUERO, 2005; ABARQUERO et al., 2013; ARNÁIZ Y MONTERO, 2011; RODRÍGUEZ MARCOS Y FERNÁNDEZ MANZANO, 2012) a los que remitimos. Destaca también por su registro funerario, analizado por extenso en ESPARZA et al., 2012a, que todavía sigue siendo problemático sobre todo porque el número de enterramientos que se conocen es exiguo, demasiado bajo para tan amplia duración y extensión territorial. Aparecen en el interior de los sitios de habitación algunos esqueletos inhumados en 'hoyos' (silos reutilizados, o excavados al efecto). Aunque generalmente son individuales, hay un llamativo número de enterramientos triples simultáneos, advirtiéndose también una diferencia entre dos tipos muy contrastados: predominan aquellos en los que el difunto fue cuidadosamente colocado, en decúbito lateral flexionado, con una marcada tendencia hacia el lado derecho para los varones e izquierdo para las mujeres; en otros, en cambio, debieron de arrojarse los cuerpos, que aparecen en decúbito prono, con las extremidades totalmente descolocadas. En todo caso, más allá del cuidado mostrado con unos y ausente con los otros, los enterramientos carecen de ajuar, lo cual aparentemente indicaría una sociedad homogénea y más bien pobre. Sin embargo, en los depósitos mortuorios hay aspectos llamativos, que invitan a pensar que el conjunto enterrado no responde a una mortalidad natural, sino a una clara selección que comprende individuos de uno u otro sexo, pero con una distribución de grupos de edad que, según las tablas de vida, excluye una mortalidad atricional. Si el análisis paleodemográfico indica la excepcionalidad del conjunto, otros rasgos lo corroboran, como la frecuencia de tumbas triples o el inusual tratamiento inclusivo de infantiles, así como el hecho el que en los hoyos queden en última instancia igualados los individuos cuidadosamente depuestos y aquellos otros que no merecieron el más mínimo respeto. Entonces, si todo el conjunto enterrado es escaso y excepcional, ¿dónde fue a parar la mayoría de la pobla- ción? Recientemente se ha propuesto (ESPARZA et al., 2012b), a partir de la observación de mordeduras de cánido y otros detalles postdeposicionales sobre dos esqueletos, que la pauta general debió de ser la exposición de cadáveres -y por ello su casi total desaparición del registro arqueológico-, mientras que aquellos individuos que tuvieron una 'mala muerte' recibieron un tratamiento excepcional, el enterramiento en hoyo, tanto en su variante respetuosa (probablemente las personas fallecidas a edades tempranas, en determinados accidentes, las mujeres muertas en el parto, etc.) como en la otra modalidad, la de quienes fueron arrojados sin contemplaciones, en la que cabría sospechar reprobación social.

Esta conducta funeraria que opone 'buena muerte' y 'mala muerte', muy bien conocida en la literatura antropológica, debió de relacionarse, junto a otras prácticas mortuorias, con una compleja ideología al servicio de la configuración y mantenimiento del orden social. En efecto, también se van hallando de forma recurrente depósitos de animales completos, o también enterramientos humanos secundarios en los que a veces se reúnen huesos de individuos cuya datación radiocarbónica es significativamente diferente. A estas manifestaciones podrían unirse otras consistentes en lo que se ha interpretado como el final del ciclo o "muerte simbólica" de ciertos artefactos, como recipientes cerámicos o cabañas (SÁNCHEZ-POLO Y BLANCO-GONZÁLEZ, 2014).

En el contexto de esas prácticas mortuorias se encuadra un insólito enterramiento cuádruple, el primero hallado en el ámbito de Cogotas I (Fig. 1). Su estudio bioarqueológico ha desvelado que -como luego se verá- a los cuatro individuos, todos ellos subadultos, se les dio muerte violentamente, abriéndose así una problemática novedosa, que rebasa ampliamente una investigación de alcance regional.

\section{EL YACIMIENTO DE LOS ROMPIZALES}

No lejos de la ciudad de Burgos, junto a la localidad de Quintanadueñas, se halla el pago de Los Rompizales (X: 437704; Y: 4691679; 832 m s.n.m.), en la zona de contacto entre el páramo calcáreo y la vega del río Ubierna, tributario del Arlanzón (Fig. 2). En septiembre de 2009, con motivo del trazado de la carretera de circunvalación de la capital, se efectuó una excavación preventiva (ANTEQUEM, 2009), que en una franja de unos $2500 \mathrm{~m}^{2}$ exhumó un "campo de hoyos" consistente en más de cien estructuras subterráneas cavadas en el terreno margoso-limoso, únicos vestigios subsistentes de una ocupación prehistórica que a juzgar por las cerámicas recuperadas corresponde solamente a la Edad del Bronce, concretamente al grupo cultural de Cogotas I. Este yacimiento, con otros alineados con los mismos ríos, aparentan una densidad atribuible a su supuesta naturaleza de aldeas de carácter inestable, con ocupaciones, abandonos y reocupaciones, en relación con la fertilidad del suelo. 

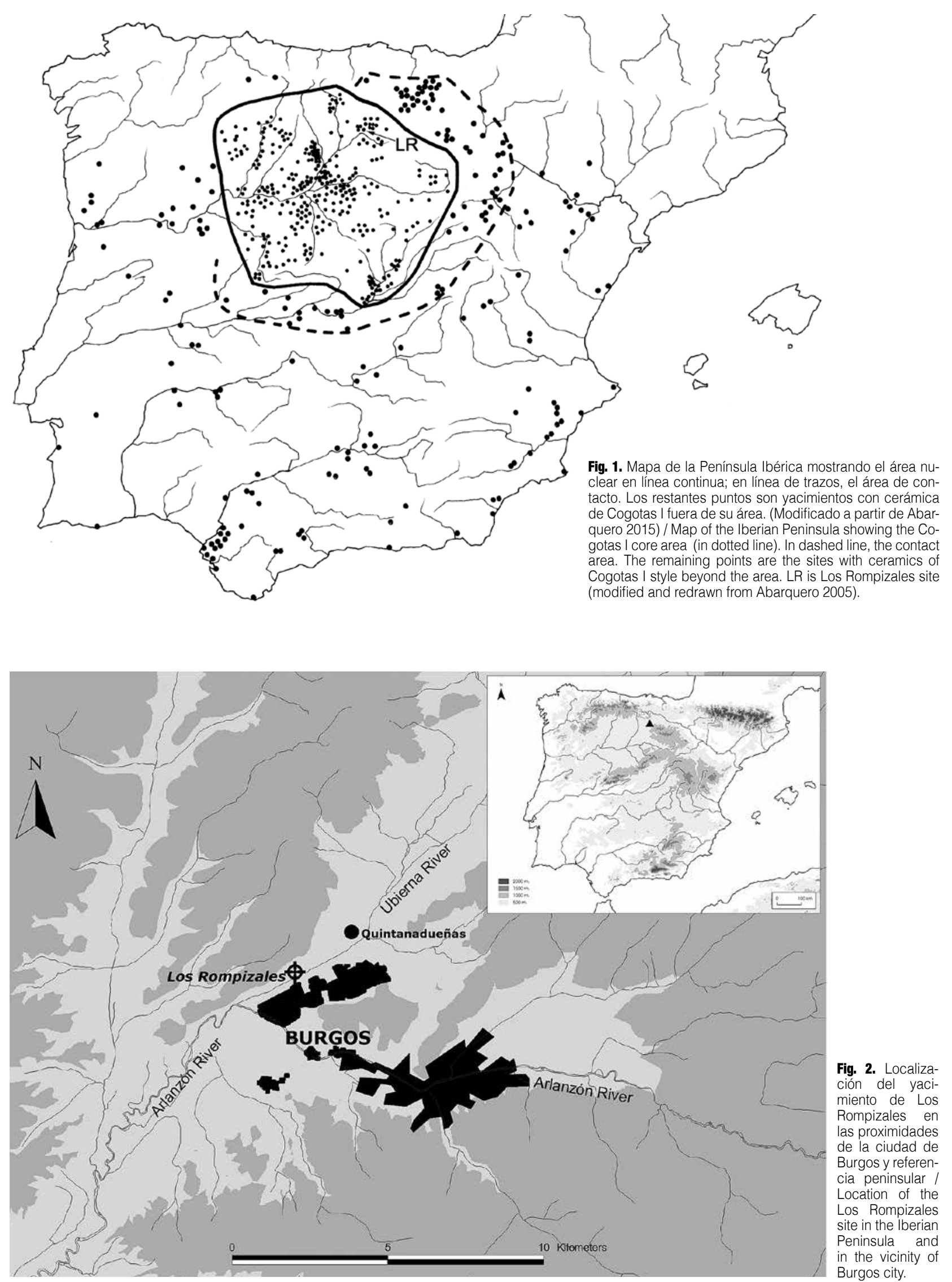

Fig. 2. Localización del yacimiento de Los Rompizales en las proximidades de la ciudad de Burgos y referencia peninsular / Location of the Los Rompizales site in the Iberian Peninsula and in the vicinity of Burgos city. 


\section{EL HOYO 64: CONTEXTO Y DATACIÓN}

Según el Informe de excavación, el hoyo núm. 64 era una de tantas estructuras subterráneas, en este caso un posible silo con una boca casi circular de 140 $\mathrm{cm}$, que se ensanchaba hacia abajo, irrelevante por lo demás en cuanto su ubicación o aspecto. Sin embargo, su excavación deparó una notable sorpresa: bajo una primera capa (UE 641) de matriz arenosa y color marrón oscuro empezaron a asomar restos humanos que, descubiertos meticulosamente, correspondían a cuatro individuos, uno en posición casi central y los otros tres adaptados a la curvatura de la pared del hoyo (Fig. 3), todos ellos depuestos sobre otra capa (UE 642) también de color marrón oscuro pero mucho más compacta que la anterior y que terminaba directamente sobre el recorte del hoyo (UE 647) en el sustrato geológico.
La UE 641, la tierra del relleno que cubría los esqueletos, probablemente procedía del nivel de ocupación, por las características de la matriz y por su contenido, que se redujo a escasos materiales sin orden ni asociación: ocho fragmentos óseos de fauna indeterminada y veinte fragmentos de cerámica a mano, entre los que destacan tres bordes (Fig. 4), uno de ellos con una decoración incisa en zigzag que puede atribuirse con gran seguridad a la fase formativa de la cultura, denominada Proto-Cogotas I (el Bronce Medio regional) (ABARQUERO, 2005, 59ss.), marcando un terminus post quem para el enterramiento, que sería exhaustivamente corroborado por las dataciones radiocarbónicas de los esqueletos. El sedimento basal (UE 642) probablemente era el relleno erosivo de un silo abandonado, que tenía unos $14 \mathrm{~cm}$ de espesor cuando los cadáveres fueron depositados.
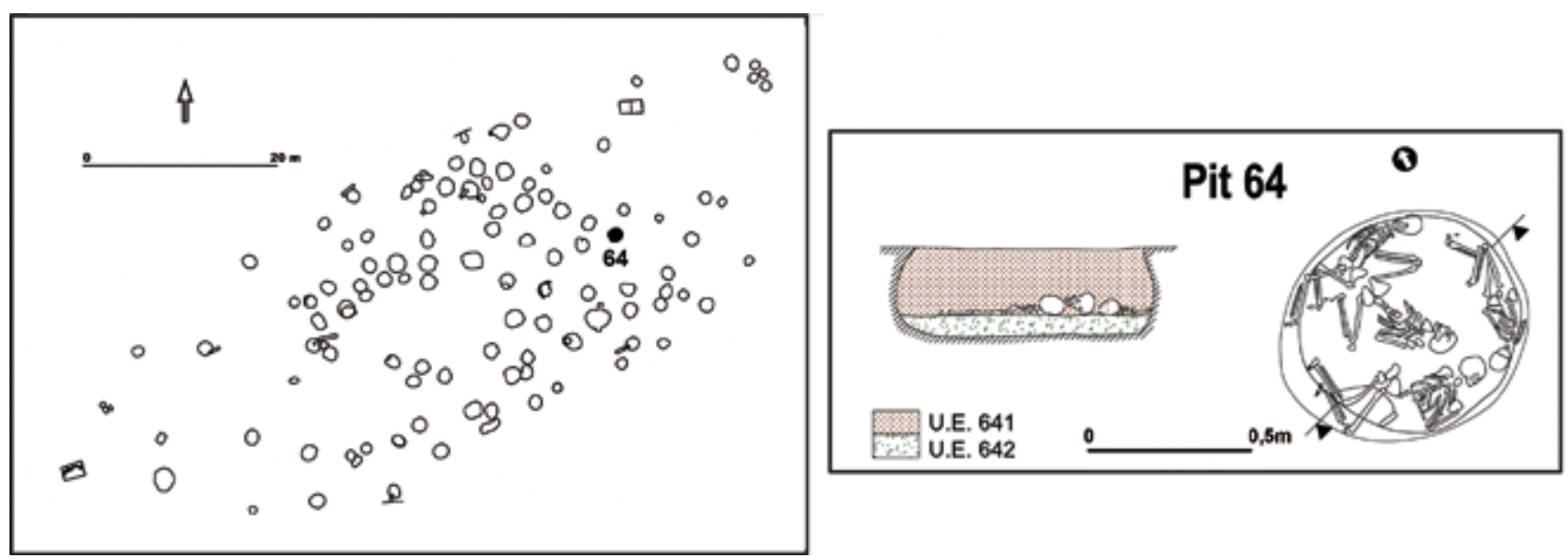

Fig. 3. El campo de hoyos excavado en Los Rompizales en relación con el trazado de la nueva circunvalación de Burgos (izda-); a la dcha., planta y sección del Hoyo 64 (A partir de Antequem 2009) / The pit-site exhumated at Los Rompizales area in connection with the new Burgos ring-road layout (left), and the Pit 64 excavation sketch (right) (modified from Antequem 2009).
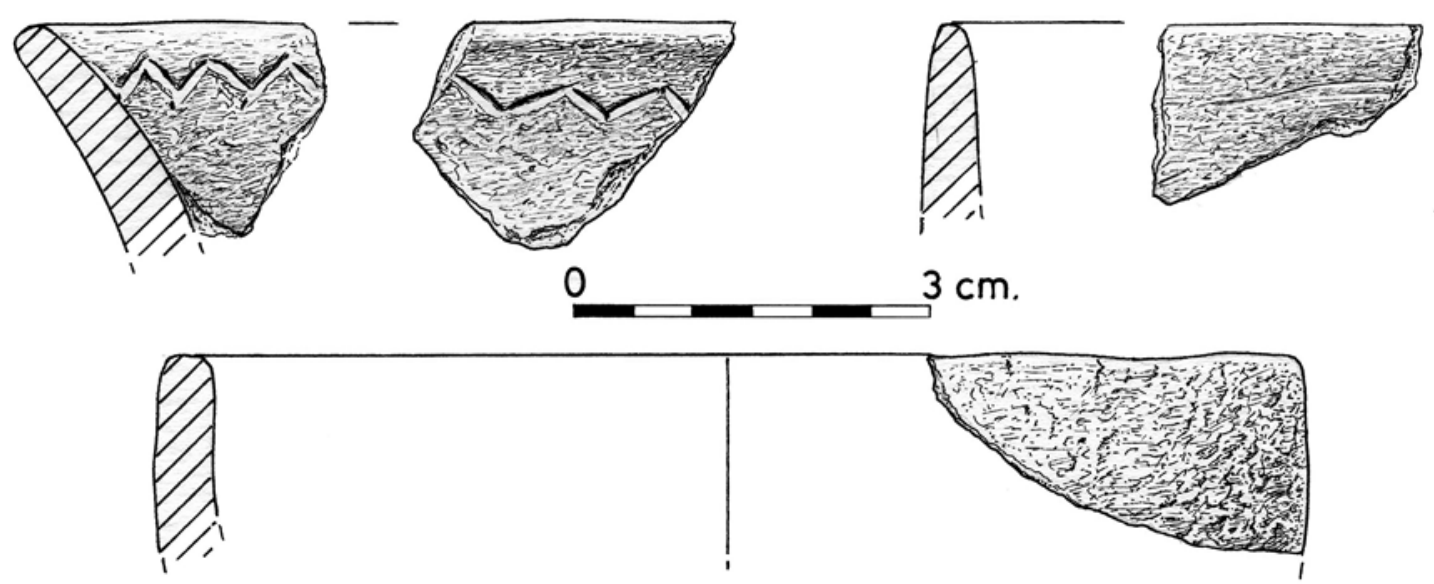

Fig. 4. Fragmentos cerámicos, entre ellos un borde asignado al estilo Proto-Cogotas I, hallados en el relleno sedimentario del Hoyo 64 / Some sherds including a decorated rim assignable to the 'Proto-Cogotas l' style retrieved in the sedimentary fill of the Pit 64. 
Una muestra del peroné derecho de cada esqueleto fue datada por AMS en el Laboratorio de Radiocarbono de Poznan, con los resultados de la tabla1:

Si en una primera aproximación meramente visual las fechas de radiocarbono pudieran dar la impresión

\begin{tabular}{|l|l|l|l|}
\hline Sample & Laboratory Ref. & Laboratory Ref. & Calibrated age (2 ) \\
\hline RPZ-01 & Poz-43659 & $3250 \pm 35$ BP & $1615-1447$ cal BC \\
\hline RPZ-02 & Poz-43660 & $3195 \pm 30$ BP & $1517-1414$ cal BC \\
\hline RPZ-03 & Poz-43661 & $3185 \pm 30$ BP & $1508-1411$ cal BC \\
\hline RPZ-04 & Poz-43662 & $3165 \pm 30$ BP & $1503-1329$ cal BC \\
\hline
\end{tabular}

Tabla 1: Dataciones radiocarbónicas / Radiocarbon datations. de cierta discrepancia, lo cierto es que sus intervalos de calibración resultan notablemente coincidentes. Pero, más allá de esa impresión, la estadística, concretamente el análisis bayesiano, permite un tratamiento riguroso de la probabilidad ${ }^{1}$.

En efecto, tales dataciones no están desconectadas, sino que corresponden a un conjunto, funerario en este caso, y el análisis bayesiano permite ensayar diversos modelos que restringen la incertidumbre teniendo en cuenta la información arqueológica previa. Así, se podría considerar en primer lugar que las cuatro fechas corresponden a una secuencia de eventos próximos, cuyo procesamiento mediante la opción "Phase" del programa OxCal arroja el siguiente resultado (Fig. 5):

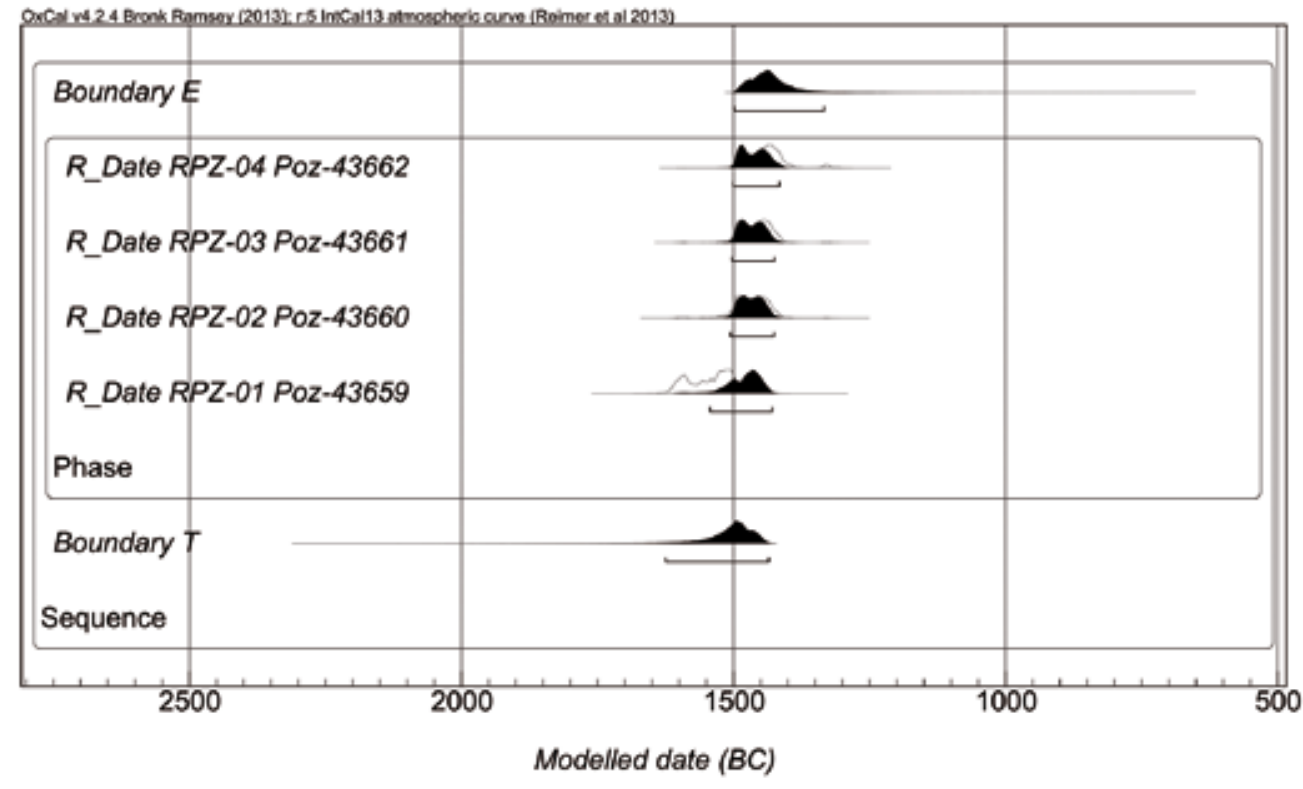

\begin{tabular}{|c|c|c|c|c|c|c|c|c|c|c|c|c|c|}
\hline \multirow{2}{*}{$\begin{array}{l}\text { Name } \\
\text { Show all } \\
\text { Show structure }\end{array}$} & \multirow{2}{*}{ 三E } & \multicolumn{3}{|c|}{ Unmodelled (BC/AD) } & \multicolumn{3}{|c|}{ Modelled (BC/AD) } & \multicolumn{4}{|c|}{$\begin{array}{l}\text { Indices } \\
A_{\text {model }}=95.2 \\
A_{\text {overall }}=97.1\end{array}$} & \multirow{2}{*}{$\begin{array}{l}\text { Select } \\
\text { All } \\
\text { Visible }\end{array}$} & \multirow{2}{*}{$\begin{array}{l}\text { Page } \\
\text { break }\end{array}$} \\
\hline & & from & to & $\%$ & from & to & $\%$ & $A_{\text {comb }}$ & A & LP & c & & \\
\hline Boundary $\mathrm{E}$ & 訏 & & & & -1499 & -1334 & 95.4 & & & & 97.1 & 09 & $\square$ \\
\hline R_Date RPZ-04 Poz-43662 & 洰 & -1503 & -1329 & 95.4 & -1501 & -1416 & 95.4 & & 98.3 & & 99.3 & 08 & $\square$ \\
\hline R_Date RPZ-03 Poz-43661 & 決。 & -1508 & -1411 & 95.4 & -1504 & -1425 & 95.4 & & 107 & & 99.4 & 07 & $\square$ \\
\hline R_Date RPZ-02 Poz-43660 & 湴。 & -1517 & -1414 & 95.4 & -1506 & -1426 & 95.4 & & 108.8 & & 99.5 & 06 & $\square$ \\
\hline R_Date RPZ-01 Poz-43659 & $\bar{E}$ & -1615 & -1447 & 95.4 & -1544 & -1430 & 95.4 & & 82.4 & & 99.4 & 05 & $\square$ \\
\hline $\boldsymbol{\Delta}$ Phase & 非 & & & & & & & & & & & 04 & $\square$ \\
\hline Boundary $T$ & $\equiv \equiv$ & & & & -1625 & -1436 & 95.4 & & & & 97.1 & 03 & $\square$ \\
\hline A Sequence & 非 & & & & & & & & & & & 02 & ㅁ \\
\hline
\end{tabular}

Fig. 5. Primer modelo bayesiano para el enterramiento de Los Rompizales (como una fase). Para cada una de las dataciones se han dibujado dos distribuciones: una, en gris, con el resultado simple de la calibración, y otra en negro basada en el modelo cronológico usado. La tabla muestra los intervalos e calibración, y también los distintos Índices de Acuerdo. / First bayesian model for Los Rompizales burial (as a phase). For each of the dates two distributions have been plotted: one, in outline, wich is the result of simple radiocarbon calibration, and a solid one, based in the chronological model used. The table shows the calibration intervals, and also the Indices of Agreement.

${ }^{1}$ Las fechas de radiocarbono obtenidas han sido calibradas mediante el programa OxCa/ v4.2.4, que utiliza la curva atmosférica intCal 13 (REIMER et al., 2013). Todo el tratamiento bayesiano ha sido realizado también mediante dicho programa (BRONK RAMSEY, 2009), aprovechando el espacio de trabajo facilitado por la plataforma on-line de la ORAU (Oxford Radiocarbon Accelerator Unit) dirigida por el Prof. C. Bronk Ramsey. 
Ahora, la probabilidad posterior de las fechas aparece representada en color negro sobre el gris de las dataciones iniciales, y sus intervalos a $2 \sigma$, como puede verse en la tabla, quedan ligeramente recortados (15411430 cal BC; 1506-1426 cal BC; 1503-1425 cal BC; $1501-1416$ cal $B C)$, y con un alto grado de coincidencia.

Finalmente, se ha efectuado otro ensayo, ya que como después se justificará a partir de observaciones estratigráficas, superposiciones y otros indicios- asumimos como información previa (prior) que el enterramiento de los cuatro individuos debió de ser simultáneo, formando las dataciones individuales un evento único. Esta restricción (constraint) será procesada por el programa OxCal mediante la opción R_Combine, que tras descartar la 'hipótesis nula' de que las fechas no sean estadísticamente diferentes - mediante $\mathrm{x} 2$-Test: $\mathrm{df}=3$ $\mathrm{T}=3.6$ (5\% 7.8) - procede a combinarlas en una nueva datación conjunta, obteniéndose como resultado (fig. 6) el intervalo más probable en el que se situaría el evento mortuorio, entre 1501-1431 cal BC.

Las dataciones radiocarbónicas, en definitiva, llevan este enterramiento a algún momento dentro de los dos primeros tercios del siglo XV cal $A C$, en el final de la fase ProtoCogotas I, confirmando la datación que se desprende de la cerámica del relleno del hoyo.

\section{EL DEPÓSITO MORTUORIO}

El hallazgo de Los Rompizales encaja en las tipologías habituales, constituyendo un ejemplo de "sepultura múltiple con cuerpos en posición organizada" (JEUNESSE, 2010: 35), aunque en este caso podría incluso discutirse el empleo del concepto de sepultura (LECLERC, 1990; BIROCHEAU et al., 1999) y, por ello, hacer hincapié en el de enterramiento.

Como se expondrá a continuación, se trata de un ejemplo que, dentro del panorama conocido hasta el momento para Cogotas I, merece sin duda el calificativo de inusual, equivalente de otros, como 'irregular burial' (MILELLA et al. 2015) o 'sepulture bizarre' (BA-
RAY Y BOULESTIN, 2010), que aluden a su carácter chocante con respecto a las habituales, o el de 'unusual burial' que TSALIKI (2008) justifica por rasgos insólitos en cuanto al lugar o a la disposición funeraria normativa, especialmente el decúbito prono. En cambio, deben evitarse —al menos en este momento del trabajo- términos como el ya clásico de 'sépulture de relegation', que su propio autor, VILLES (1986), utiliza ahora con mucha prudencia, ya que debe demostrarse que hubo efectivamente relegación social. Algo parecido ocurre con el de 'deviant burial', pues diversos autores, como SHAY (1985), también lo reservan para aquellos casos en los que se dispone de evidencia probatoria de esa "desviación" social, como signos de enfermedades especiales, singularidad étnica, etc.

Disquisiciones terminológicas aparte, lo cierto es que el depósito fúnebre está integrado por cuatro individuos que fueron incluidos simultáneamente (o con escasa separación entre unos y otros) en el interior del hoyo ocupando buena parte del fondo de la estructura. Tal disposición no es producto del azar: uno de ellos es situado en la zona central del espacio de inhumación, y los otros tres lo circundan pegados a la pared del hoyo. El sujeto localizado en el centro (Individuo núm. 1) fue dispuesto en decúbito prono, con ambas piernas abiertas y semiflexionadas, describiendo una figura simétrica con respecto a su eje axial. Los tres satélites fueron colocados en decúbito lateral, con piernas y brazos flexionados, acomodándose cada cadáver a la curvada pared interior del hoyo. Además, se quiso que quedasen de espaldas al sujeto central, circundándolo completamente (Fig. 7).

Esa meticulosa composición de conjunto -que evoca la 'aesthetics of deposition' que POLLARD (2001) planteaba para ciertas prácticas del Neolítico británico-sería el primer argumento en favor de la simultaneidad del entierro. Sobre ello abundan las observaciones de campo, pues los restos esqueléticos se apoyaban sobre el mismo fondo homogéneo casi compacto y todos ellos estaban recubiertos por un mismo sedimento; además, se advirtió también la parcial superposición di-

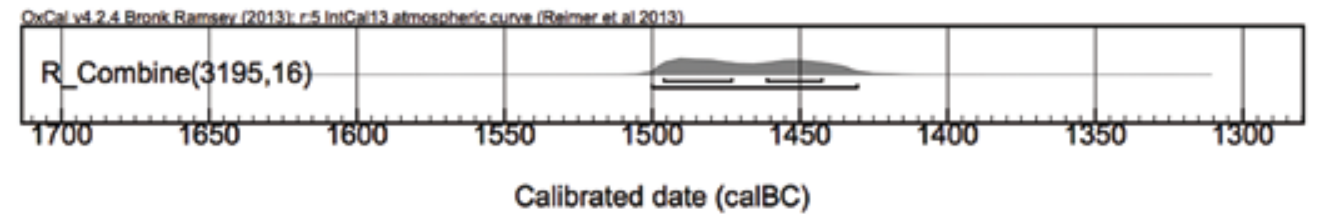

\begin{tabular}{|c|c|c|c|c|c|c|c|c|c|}
\hline Name & & Unmo & delled & (BC/ & /AD) & & & & Paqe \\
\hline $\begin{array}{l}\text { Show all } \\
\text { Show structure }\end{array}$ & & from & to & $\%$ & from & to & $\%$ & $\begin{array}{l}\text { All } \\
\text { Visible }\end{array}$ & break \\
\hline R_Combine $(3195,16)$ & ) & -1497 & -1443 & 68.2 & -1501 & -1431 & 95.4 & $\nabla 2$ & $\boxminus$ \\
\hline
\end{tabular}

Fig. 6. Segundo modelo cronológico (evento único), combinando las cuatro dataciones / Second chronological model (single event), combining the four dates. 


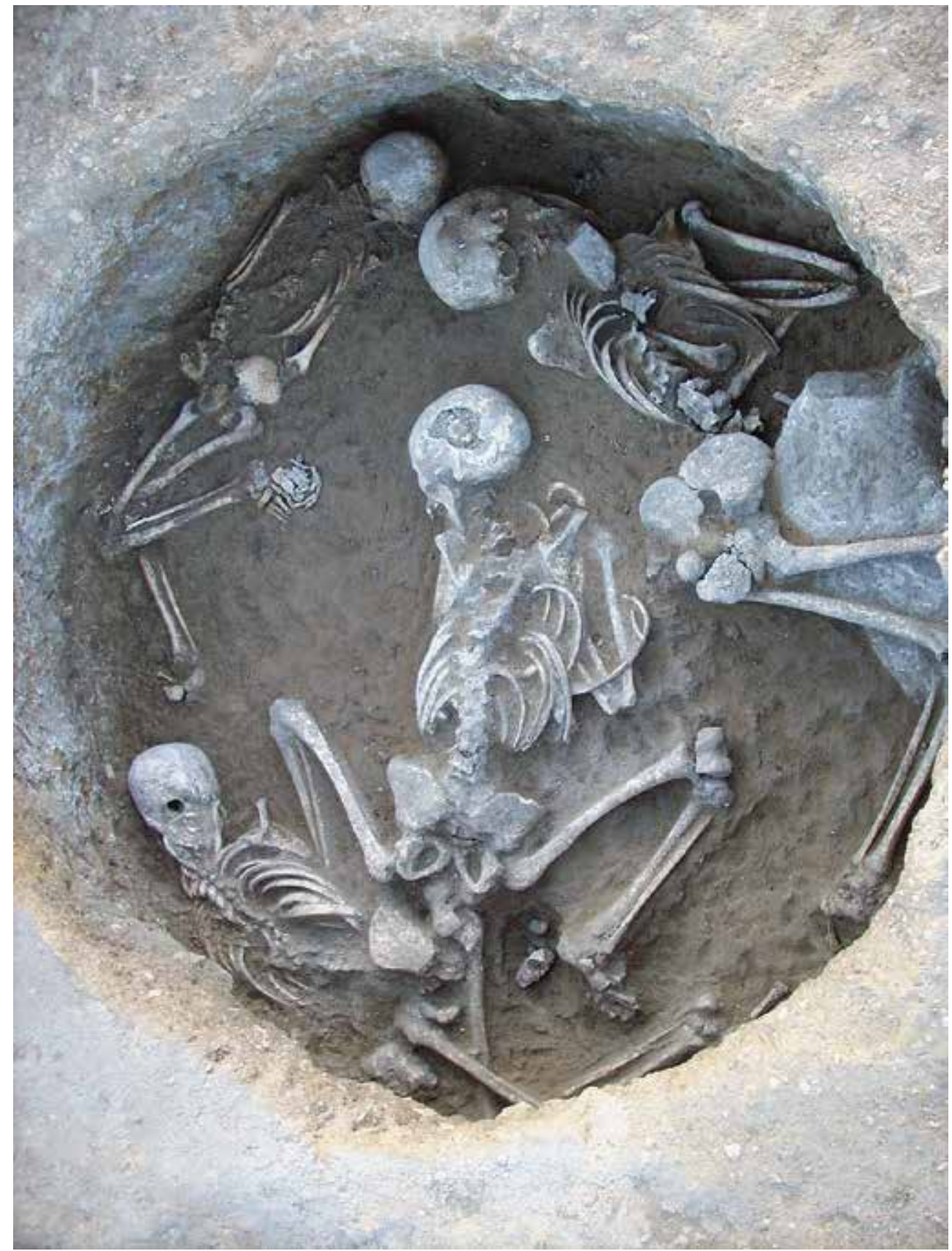

Fig. 7. El hoyo 64 de Los Rompizales durante el proceso de excavación (Foto cortesía de D. Luis Villanueva) / Pit burial 64 during excavation process (Photo courtesy of Mr. Luis Villanueva). recta del Individuo $\mathrm{n}^{\circ} 2$ sobre el 1. Parece en definitiva que el espacio reservado a los cadáveres fue concebido de forma unitaria, y la ordenación se habría conformado en un único e intencionado gesto deposicional.

Lo dicho quedaría avalado también por las condiciones en que se produjo la descomposición de los cuerpos: en efecto, la natural degradación que sufrieron los cadáveres una vez depositados en el hoyo fue homogénea, observándose unos efectos posdeposicionales equiparables en los cuatro individuos. Siguiendo la terminología propuesta por DUDAY (2005, 2009), sufrieron un proceso de descomposición en un espacio abierto. El Individuo $\mathrm{n}^{\circ} 1$ ejemplifica ese fenómeno, al mostrar desplazamientos de porciones anatómicas que no habrían tenido lugar si hubiera sido cubierto directamente por tierra. Las costillas derechas protagonizaron movimientos de cierta envergadura, trasladándose en dirección derecha y superando incluso los límites del volumen inicial del cuerpo. Destaca el alejamiento de la primera y segunda costilla de su emplazamiento anatómico o el de aquellas piezas costales que finalmente quedan apoyadas sobre el húmero derecho (que se desplaza también hacia lateral, perdiendo su vinculación con la cintura escapular y manteniendo su asociación con cúbito y radio). Otros movimientos, como los 
del cráneo o las vértebras, y la baja intensidad de los documentados en el lado izquierdo, hacen pensar que en el momento inicial del depósito la mitad derecha del cuerpo se encontraba ligeramente más elevada, horizontalizándose luego en el curso de la descomposición.

Los otros tres individuos, colocados perimetralmente, padecieron circunstancias semejantes, con ligeras variaciones en la disposición inicial de los cuerpos y el punto concreto en el que quedaron ubicados. Por ejemplo, el Individuo $\mathrm{n}^{\circ} 2$ se encontraba casi en decúbito lateral derecho en el momento del depósito inicial, pero el retardo de la entrada de sedimento en contacto con el cadáver permitió unos movimientos característicos: el cráneo se desplaza hacia delante, posiblemente coincidiendo con el hundimiento en bloque del raquis cervical que, salvo el atlas, bascula hacia la derecha. Buena parte de las dorsales y las costillas caen conjuntamente hacia la izquierda, aunque en un movimiento de intensidad moderada y limitada por el borde del hoyo. La basculación hacia medial del coxal derecho motiva la desconexión del fémur de su acetábulo y de la articulación sacroilíaca.

El Individuo $\mathrm{n}^{\circ} 3$ se comporta de forma análoga, apreciándose el desplazamiento conjunto hacia el borde del hoyo, indicativo, además, de una disposición inicial próxima al decúbito lateral. En este caso el desplazamiento de las cervicales es menos evidente - descienden en bloque, incluido el atlas, sin desplazamiento lateral- justo al contrario que las lumbares, que rotan hacia el lado izquierdo desalineándose con respecto al resto de la columna. Esta situación es coherente con lo observado en los coxales, que caen hacia ese flanco perdiendo sus asociaciones anatómicas. Esta traslación es menos intensa en el derecho que en su contrario, pues éste se encontraba a mayor altura y, por ello, rota prácticamente $180^{\circ}$. El fémur de este mismo lado había descendido previamente, desvinculándose del acetábulo y la tibia, mientras que los tarsos de ambas piernas se desligaban casi por completo.

Finalmente, el Individuo $n^{\circ} 4$ muestra algunos rasgos particulares relacionados con la presencia de una gran piedra en el borde más meridional del hoyo, sobre la que quedó apoyada prácticamente la mitad inferior del cuerpo, lo que provocó que las piezas del raquis sufrieran importantes movimientos: las lumbares descienden en bloque, perdiendo algunas de ellas la conexión, y las dorsales sufren también esta alteración aunque con menor intensidad, para finalmente quedar mayoritariamente en posición dorsal; ambas palas iliacas caen hacia la izquierda, disociándose fémures y sacro. Merece atención especial el movimiento de las cervicales y el cráneo, ya que las primeras descienden en conjunto y el segundo bascula hacia la izquierda y adelante.

La totalidad de fenómenos descritos ilustran claramente en el depósito el citado fenómeno de descomposición en espacio abierto. En este contexto el sedimento no entra en contacto con los restos humanos, al menos de forma homogénea y generalizada, sino en un momento avanzado del proceso de descomposición, propiciando movimientos postdeposicionales como los descritos. Por su parte, la pérdida completa de asociaciones anatómicas en las conexiones permanentes, además de en aquellas de naturaleza lábil, indica que la tierra tardó cierto tiempo en envolver por completo los esqueletos (DUDAY, 2005, 2009; HARRIS Y TAYLES, 2012). Ello se debió a que los cuerpos depositados fueron tapados con algún elemento, de naturaleza perecedera puesto que nada se halló en la excavación.

Pese a la presencia de desconexiones en las articulaciones permanentes de los cuatro individuos de Los Rompizales, si se atiende al tipo y a la magnitud de los desplazamientos - la mayor parte de ellos restringidos al volumen inicialmente ocupado por el cuerpo y directamente asociados a la posición primaria de los cadáveres- el elemento que los protegió no debió de ser de un material completamente rígido, que hubiera podido generar un compartimento estanco (DUDAY Y GUILLON, 2006: 139-140; HARRIS Y TAYLES, 2012: 232-233), tratándose tal vez de pieles, mantas, ramaje, etc.

En suma, el escenario más plausible es que se trata de un evento único (estrictamente simultáneo, o bien con una separación muy corta), como se desprende de los rasgos que se han expuesto: a) Sobre todo, por la meticulosa disposición de los cuerpos, que parece indicar una concepción de conjunto de lo que había de hacerse con todos y cada uno de ellos. b) La superposición, probada entre los individuos 2 y 1. c) Los mismos procesos postdeposicionales afectan a los cuatro. d) Todos parecen haber ido sobre el mismo sedimento, quedando envueltos por un relleno muy uniforme. e) Parecen haber estado tapados por un solo elemento cobertor. f) No se vieron afectados por carroñeo en ningún caso.

\section{LOS INDIVIDUOS DEPOSITADOS}

El estudio de las particularidades bioantropológicas de los inhumados puede sumar datos de interés para explicar la naturaleza del depósito y de los gestos sociales que lo originaron. En este sentido el primer aspecto a tener en cuenta, y que determina además los procedimientos para su caracterización, es que los cuatro individuos murieron antes de alcanzar la edad adulta. Esa condición de subadultos permite establecer con bastante precisión la edad a la que fallecieron, gracias al pautado grado de desarrollo y maduración ósea y dental de nuestra especie; por contra, la determinación del sexo a partir del material esquelético resulta en esos grupos de edad un ejercicio de limitada precisión diagnóstica, ya que, como es sabido, hasta la madurez no se configuran definitivamente los rasgos de mayor capacidad discriminante. A pesar de todo, se efectúa una atribución tentativa del sexo de cada uno de los individuos, algo más verosímil en aquellos sujetos de mayor edad.

La edad de muerte se ha determinado a partir del grado de erupción y desarrollo de las piezas dentarias, 
así como la fase de maduración de las piezas esqueléticas de cada uno de los inhumados (BUIKSTRA Y UBELAKER, 1994; KLEPINGER, 2006). En cuanto a la estimación del sexo se han aplicado los criterios adaptados a este segmento de población propuestos por varios autores (SCHEUER Y BLACK, 2000; KLEPINGER, 2006; KRENZER, 2006; LEWIS, 2007). El importante grado de incertidumbre de estos métodos requiere el apoyo de un procedimiento de alto poder diagnóstico como los análisis de $\mathrm{ADN}^{2}$, concretamente la 'prueba de la amelogenina' para establecer el 'sexo molecular' de los cuatro individuos.
Resumiendo los distintos análisis (Fig. 8) diremos que en el centro del hoyo se situó un varón (Individuo $\mathrm{n}^{\circ}$ 1) de edad comprendida entre 12 y 13 años. El Individuo $\mathrm{n}^{\circ} 2$, apoyado sobre el anterior, corresponde a un sujeto femenino, una chica fallecida entre los 15 y los 17 . Un niño de 7-8 años, el más joven del depósito, ocupaba el extremo oriental del hoyo $\left(n^{\circ} 3\right)$ y, junto a él, otro chico de 12-13 años ( $\left.n^{\circ} 4\right)$. Así, siguiendo la nomenclatura de SCHEUER Y BLACK (2000), este depósito de Los Rompizales queda integrado por un infantil y tres adolescentes, es decir, un 'perfil demográfico' que, a priori, podría calificarse de singular porque precisamente en

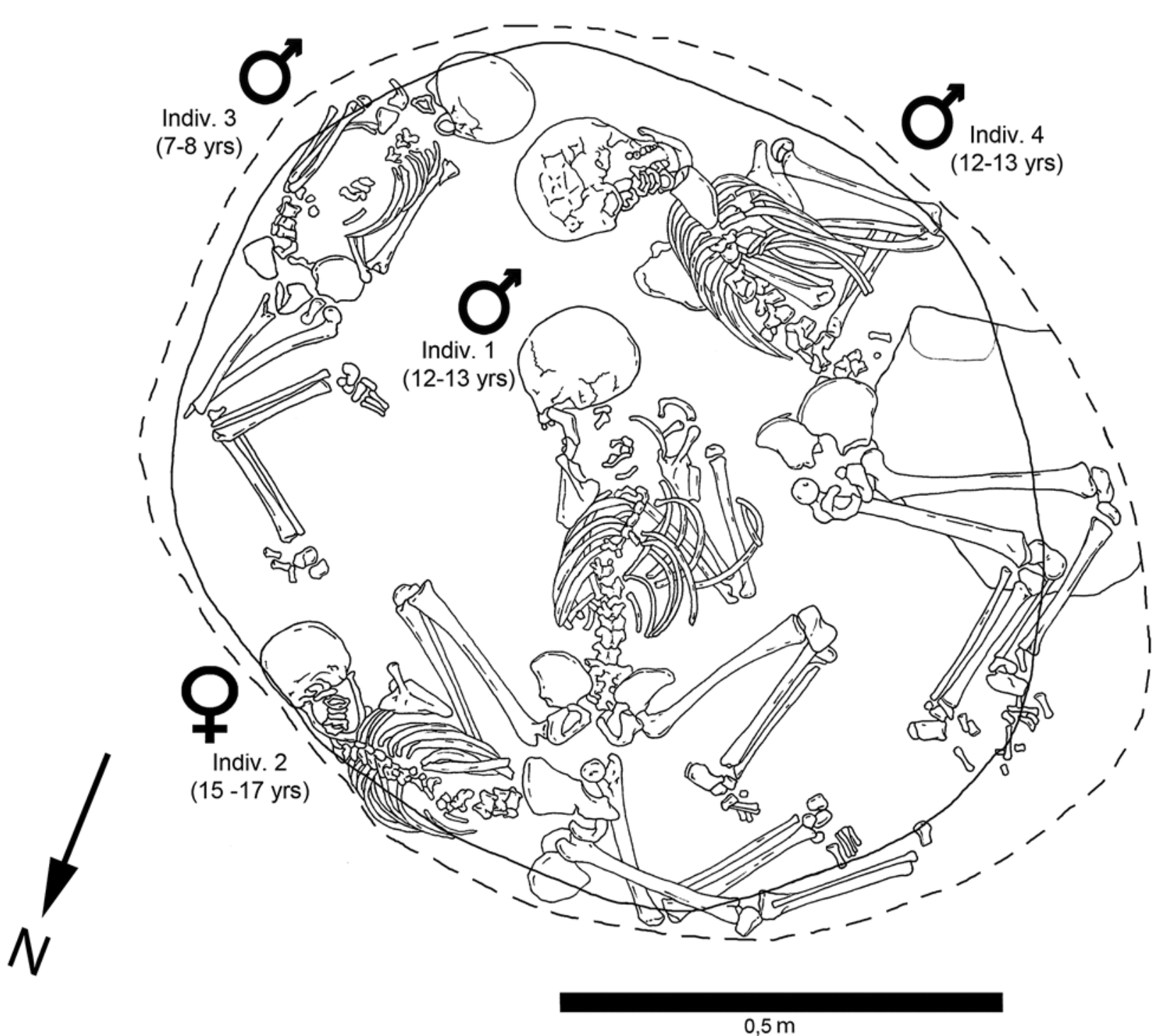

Fig. 8. Edad y sexo de los individuos enterrados en el hoyo 64 / Age and sex of the individuals buried in the pit 64 .

${ }^{2}$ Los análisis han sido realizados en su tesis doctoral por Sara PALOMO DíEZ (2015) en el Laboratorio de ADN Antiguo del Grupo de Investigación de Genética Forense y Genética de Poblaciones (Facultad de Medicina, Universidad Complutense de Madrid), dirigido por el Dr. Arroyo Pardo. 
estos rangos de edad los índices de mortalidad suelen ser más bajos que los detectados en otros segmentos (SELLIER, 1995; DURAND, 2008; GONZÁLEZ MARTÍN, 2008). Sin embargo, este rasgo no resulta tan llamativo en el contexto concreto de Cogotas I de la Submeseta Norte, pues en el conjunto poblacional estudiado hasta el momento (ESPARZA et al., 2012a) los subadultos suponen algo más del $40 \%$ del total de la muestra y, más específicamente, un $26,5 \%$ los fallecidos entre los 5 y los 18 años; y el cálculo del índice de Juventud $(\mathrm{IJ}=0.316)$ mostraba un sesgo de esta población hacia los más jóvenes. Ya se argumentaba entonces que porcentajes tan elevados de infantiles y juveniles podrían estar reflejando o bien una particular mortandad en estas cohortes de edad o, más probablemente, que su presencia en los hoyos fuera el resultado de una selección directamente vinculada a la excepcionalidad de las circunstancias o condiciones de su muerte, lo cual —planteábamos como hipótesis - los excluyó del tratamiento funerario normativo.

El de Los Rompizales tampoco es el único hoyo que en Cogotas I ha deparado un depósito múltiple de subadultos: por ejemplo, en El Cerro-La Horra (PALOMINO et al., 1999; ESPARZA et al., 2012a) se inhumó en un breve lapso a tres individuos, una niña de 7-8 años y dos varones de 10-11 y de 12-15 años, que debían de ser hermanos, como está probado genéticamente en el caso de los dos últimos. Sin embargo, y si bien es cierto que comparten rasgos (simultaneidad y perfil demográfico básicamente), ambos casos muestran también unas desemejanzas que impiden hablar de un patrón común en lo que se refiere a los gestos que dan lugar a sendos entierros: la primera, en cuanto a parentesco, y la segunda, en el tipo de muerte. En efecto, a diferencia de lo registrado en La Horra, los análisis paleogenéticos ${ }^{3}$ excluyen el parentesco cercano entre los enterrados en el hoyo 640 de Los Rompizales que, además, y como va a exponerse a continuación, fueron víctimas de una muerte violenta.

\section{EVIDENCIAS DE VIOLENCIA}

La determinación de la causa de la muerte en casos arqueológicos, constituye, salvo contadas excepciones, una labor compleja, pues en pocos casos se conservan indicios inequívocos en este sentido. Desde luego, aun en el caso de que la causa del fallecimiento haya podido quedar reflejada en el esqueleto, sería esencial que en el momento mismo de la intervención arqueológica se efectuase un registro muy riguroso (JURMAIN Y BELLIFEMINE, 1997; ROBERTS, 2000; ETXEBERRIA, 2003; ROKSANDIC et al., 2006), ya que difícilmente podrá contarse más tarde con los datos imprescindibles para una adecuada etiología.
En el caso de Los Rompizales se ha determinado que el fallecimiento de todos los individuos puede asociarse directamente o indirectamente a un episodio de violencia intencionalmente dirigida contra ellos. Eso sí, con diferencias evidentes en la forma en la que se les dio muerte y el modo y lugar en el que fueron colocados sus cuerpos en el hoyo.

\section{7a) Cráneos fracturados}

Tres de los individuos, los situados en decúbito lateral junto a la pared interior del hoyo, presentan en su cráneo traumatismos contusos que, como defenderemos, debieron de ser la causa directa de su muerte. Conviene señalar que tales lesiones fueron reconocidas en el laboratorio, puesto que en el campo los cráneos fueron extraídos sin limpiarlos del todo y con la tierra que los rellenaba.

El individuo $\mathbf{n}^{\circ} \mathbf{2}$ (Figs. 9 y 12) presenta en ambos lados del cráneo diversas líneas de fractura, paralelas y con trayectoria superoposterior-anteroinferior, manifiestas especialmente en el lado derecho, afectando sobre todo al parietal y el temporal y a ese lado del frontal. En el área entre las suturas coronaria, escamosas y la esfenoparietal, se aprecia un ligero hundimiento de la capa externa del hueso, que no presenta fracturas asociadas posiblemente porque la irradiación de la fuerza ocasionado por el trauma se transmitió a través de las antedichas suturas (KNÜSEL, 2005: 58; SHKRUM Y RAMSAY, 2007: 525). Las tres fisuras más perceptibles en este flanco del cráneo tienen una disposición prácticamente paralela, con mayor recorrido las dos que ocupan una posición más caudal. Debe destacarse la fractura de dirección anteroposterior que afectando al parietal se desarrolla sobre la superficie lateral del frontal, recorre la órbita ocular, para luego descender y discurrir transversalmente por el hueso maxilar. En este caso, la transmisión de la fuerza por el cráneo tiene su encaje en los modelos descritos por René Le Fort (LOVELL, 2008: 353), concretamente con su tipo I (que termina separando el área palatina del maxilar) y III (a través de las suturas frontozigomáticas y la órbita, que distancia el esqueleto facial de la base del cráneo), y que es habitual se presenten combinadas. Sin abandonar el lateral derecho del cráneo, a las tres descritas debe sumarse una cuarta fractura lineal que, también en paralelo a las anteriores, muestra una trayectoria coincidente con las suturas lamboidea y la occipitomastoidea para luego transcurrir lateralmente por la base del occipital hasta alcanzar el temporal opuesto.

En el lado izquierdo del cráneo se distinguen dos nuevas fracturas lineales que afectan básicamente al parietal de este lado y, en menor proporción, al frontal, y parecen corresponder a lesiones reflejadas a raíz de la fuerza del impacto en el lateral opuesto de la cabeza.

\footnotetext{
${ }^{3}$ Los análisis de ADN, tanto nuclear como mitocondrial, realizados por Sara Palomo Diez (vid. nota 2) excluyen — provisionalmente, a falta de la repetición de resultados con segunda muestra — la posibilidad de que sean hermanos o parientes muy próximos.
} 
El Individuo $\mathbf{n}^{\mathbf{3}} \mathbf{3}$ (Figs. 10 y 12) muestra un traumatismo con hundimiento localizado en mitad inferior del occipital, concretamente en su lado derecho. Desde la zona deprimida, en la que se genera una lesión conminuta, arrancan distintas fracturas radiales y concéntricas que se extienden por la base del cráneo afectando en sus extremos a los dos parietales configurando fisuras de dirección ínfero-superior, pero que también transcurren por las suturas temporales, básicamente por el lateral derecho (LOVELL, 2008: 351), llegando a afectar a una parte del lado izquierdo del frontal. El punto en el que se ejerció la fuerza se sitúa, pues, en la región basal del cráneo, emplazamiento desde el que se generan líneas de fractura, algunas de las cuales siguen las áreas de debilidad generadas por las suturas, el menor grosor del hueso o los forámenes localizados en esta región (ibid:: 358). Asociadas a ellas se identifican algunos deslascados que afectan a la tabla externa del cráneo y preferentemente en torno al hundimiento de la base craneana (SAUER, 1998; KNÜSEL, 2005; HART, 2005; GAITHER Y MURPHY, 2011: 470).

Finalmente, el Individuo $\mathrm{n}^{\circ} 4$ muestra (Fig. 11 y 12) una fractura con hundimiento localizada en la parte posterior del parietal derecho, afectando también al occipital y temporal del mismo lado. La intensidad de la fuerza aplicada al cráneo en este punto produjo una importante concavidad que afecta tanto a la tabla interna como a la externa, y una fractura conminuta que compromete a parietal, occipital y temporal, y evidencia también la gran presión ejercida en esta zona de la bóveda. Como resultado se originan líneas de ruptura radiales que tienen su centro en el área donde el hundimiento alcanza mayores proporciones. La mayor parte de ellas, culminan en la fractura concéntrica que marca el diámetro máximo del área deprimida, lo que termina dando al conjunto un característico aspecto de "tela de araña" repetidamente descrito en la bibliografía.

La potencia del golpe provoca que algunas de las líneas de fractura se extiendan por la base del cráneo, afectando también al frontal y al esqueleto facial. En esta región se observa cómo el trauma sigue las trayectorias tipo descritas por Le Fort, semejantes a las referenciadas para el Individuo $n^{\circ} 2$, y que afecta a las órbitas y al maxilar, combinándose de nuevo los tipos Le Fort I y III (LOVELL, 2008: 352-353). Añádase que por la intensidad del golpe en algún caso quedan desalineadas las porciones de hueso rotas, hecho muy perceptible en el frontal.

\section{7b) El momento de las fracturas: ¿antemortem,} perimortem o post mortem?

Teniendo en cuenta las características de las fracturas descritas, el primer paso para determinar su naturaleza es situar en qué momento se produjeron, aplicando los criterios bien establecidos en la literatura bioantropológica y forense, que permiten distinguir lesiones acaecidas antes o en torno a la muerte frente a resultados de procesos posdeposicionales. En el caso de Los Rompizales, y aplicando las propuestas de varios autores (BERRYMAN Y JONES, 1996; SAUER, 1998; BOTELLA et al., 2000; ETXEBERRIA, 2003; KNÜSEL, 2005; HART, 2005; CALCE Y ROGERS, 2007; LOVELL, 2008; SYMES et al., 2012) concluiremos que, por cumplir todos los requisitos, los tres individuos sufrieron traumatismos craneales perimortem, esto es, acontecidos en torno al momento de su fallecimiento.

La configuración y localización de las líneas de fractura descritas son un primer indicio para descartar su atribución a procesos tafonómicos sucedidos tras el entierro de los cadáveres (LOVELL, 1997: 141-144, 149; LESSA Y MENDONÇA, 2004: 379-382; KANZ Y GROSSCHMIDT, 2006: 209-211). Si a ello se une en los tres cráneos el aspecto, el ángulo de fractura y la coloración del borde, debe desecharse la idea de que la ruptura de los tejidos óseos del cráneo fuera consecuencia, por ejemplo, de la presión ejercida por el sedimento que rellenaba el hoyo o de otros procesos posdeposicionales análogos. Las características de los márgenes de las fracturas - tanto la apariencia del borde como su biselado_ y el modo en el que se propagan por la bóveda craneana indican que en el momento del trauma el tejido óseo mantenía plenamente su plasticidad, de tal suerte que siguen un patrón de quiebra específico y recurrente en las lesiones perimortem (HART, 2005: 1-2; SHKRUM Y RAMSAY, 2007: 524; LOVELL, 2008: 350-351). A la misma conclusión apuntan otros indicios, como los hundimientos de las porciones de la calota afectadas por la fuerza de impacto, las características lesiones conminutas, la expansión de las fracturas siguiendo una pauta radial y concéntrica (en los individuos $n^{\text {os }} 3$ y 4) o en líneas paralelas (en el $n^{\circ} 2$ ), y el "desconchado" de la tabla externa del cráneo asociado siempre a las líneas de ruptura (SYMES et al., 2012).

Además, ninguna de las fracturas muestra signo alguno de reacción ósea, esto es, no hay evidencia de recuperación o cicatrización de los tejidos afectados, lo que viene a corroborar que tales lesiones solo pudieron acontecer en torno a la muerte de estos individuos. Los golpes que provocaron las lesiones descritas debieron de ser muy probablemente la causa directa de la muerte de estas tres personas.

\section{7c) La naturaleza de los traumas}

Aunque la bibliografía arqueológica sobre traumatismos es muy abundante, tanto en casos concretos como en contribuciones metodológicas (bioantropológicas y forenses), las referencias a este tipo de lesiones en individuos infantiles y adolescentes es bastante menos frecuente: como se ha señalado (LEWIS, 2007: 1636; JIMÉNEZ-BROBEIL et al., 2007: 189-190; GAITHER Y MURPHY, 2011: 1-2; GAITHER, 2012: 68-69), el sesgo de la muestra, la mala conservación y el tratamiento funerario diferencial contribuyen a la escasa recuperación de subadultos completos en muestras arqueológicas 
de restos óseos humanos. Añádase que las fracturas en los no adultos suelen mostrar particularidades tanto en los mecanismos de acción que las provocan, como en la respuesta de sus tejidos óseos ante la fuerza que motiva su ruptura (JOHNSTONE Y FOSTER, 2001: 21; SCHWARTZ Y HOLT, 2003: 63; LOVELL, 2008: 352, 375).

Los daños documentados en Los Rompizales son compatibles con traumatismos contusos directos, es decir, fracturas provocadas sobre el cráneo por el impacto violento de un elemento contundente (LOVELL, 1997: 149-150; BOTELLA et al., 2000: 88; BOYLSTON, 2000: 361-362). Tanto las rupturas lineales descritas en el Individuo $\mathrm{n}^{\circ} 2$, como, y especialmente, las lesiones conminutas del hueso asociadas a hundimientos de la bóveda y fracturas radiales y concéntricas presentes en los sujetos 3 y 4 , son una muestra evidente de este tipo de heridas contusas (BERRYMAN Y JONES, 1996: 4-5; ROBERTS Y MANCHESTER, 2007: 108-109; SHKRUM Y RAMSAY, 2007: 524-526; LOVELL, 2008: 350-351). En este sentido, se ha señalado (BOYLSTON, 2000: 359; CUNHA Y PINHEIRO, 2005-2006: 235, KNÜSEL, 2005: 55; LOVELL, 2008: 350; ROBERTS Y MANCHESTER, 2007: 109; SYMES et al., 2012) que el aspecto final de las fracturas varía en relación con distintas variables, unas relativas al golpe -magnitud, duración, y dirección-, otras al elemento que afecta a los tejidos óseos, y otras al propio individuo que lo recibe — sus características físicas, la posición en que se hallaba, zona del cráneo involucrada- , sin olvidar algunas como el tipo de elemento que incide sobre el tejido óseo, el llevar o no la cabeza protegida, etc.

Así pues, los individuos 2, 3 y 4 de Los Rompizales sufrieron traumatismos contusos debidos a sendos golpes violentos en sus cráneos mediante algún elemento contundente, muy probablemente de morfología roma. En otras palabras, una lesión perimortem causada por una fuerza compresiva que afectó a la bóveda craneana, fracturando el díploe y la tabla interna (SYMES et al., 2012). En este sentido, la bibliografía especializada es prácticamente unánime a la hora de señalar que lesiones semejantes a las descritas son atribuibles, en la mayor parte de los casos, a golpes directos generados en un episodio de violencia. No obstante, es necesario profundizar en esta cuestión concreta, más aún teniendo en cuenta las especificidades de las fracturas en infantiles/ adolescentes, así como las advertencias hechas por algunos autores frente a una asociación directa entre violencia y cierto tipo de lesiones traumáticas (LOVELL, 1997; 2008; WILLIAMSON et al., 2003; JACKES, 2004; JUDD, 2008)

\section{7d) ¿Accidente, enfrentamiento u otras formas de violencia?}

Como ya adelantábamos, algunos autores han centrado su atención en las particularidades de los traumatismos craneales en subadultos y, en especial, en las causas y motivaciones a las que atribuir su origen, no siempre semejantes a las que se describen en adultos (SCHWARTZ Y HOLT, 2003: 63; WALDRON, 2009: 150). Ciertamente resulta de sumo interés determinar en el marco de qué acciones y situaciones se produjeron las fracturas de los cráneos de los tres individuos de Los Rompizales, siendo muy importante para ello disponer de todo el esqueleto, pues su observación conjunta ayuda a precisar el alcance de la lesión y también a discriminar su origen más probable (ROBERTS, 2000: 345).

Pues bien: No se documentó ningún tipo de lesión traumática -ni perimortem, ni cicatrizada o en proceso de curación - en los esqueletos postcraneales de ninguno de los tres individuos descritos ahora. Es decir, las fracturas se localizan únicamente en el cráneo, no habiéndose visto afectada, al menos en apariencia, ninguna otra región corporal. Aunque no siempre es fácil distinguir entre agresión y un cuadro accidental, la particular naturaleza y localización de los traumatismos identificados en Los Rompizales, nos lleva a plantear como opción más probable que fueran el producto de un golpe intencionalmente propinado por un agresor.

En el intento de precisar esa conducta violenta, no se debe descartar, en primer lugar, que tales lesiones fueran el producto de "maltrato infantil", concepto de aplicación problemática para sociedades prehistóricas — dado que la naturaleza del abuso físico en el pasado pudo ser bastante diferente al que en la actualidad se describe en la literatura forense (WALKER et al., 1997: 201-205) - y no demasiado reconocido arqueológicamente (LEWIS, 2007: 181-183; LOVELL, 2008: 375; GAITHER, 2012: 70-75). Pero si se aplican los criterios empleados en la práctica forense actual para reconocer el maltrato, entonces se concluye que las lesiones observables en Los Rompizales no se ajustan a lo descrito como más habitual en esa conducta. Así, y sin ánimo de exhaustividad, el tipo de daño, la localización exclusiva en el cráneo y la ausencia de otras fracturas previas consolidadas o en proceso de curación (CRAMER Y GREEN, 2003: 709, 718; LEWIS, 2007: 180-181; BILO et al. 2010: 3-5) bastarían para concluir que las incidencias observadas en los sujetos de Los Rompizales no son en absoluto semejantes a las descritas para casos actuales de abuso infantil.

En segundo lugar cabe abordar el conflicto bélico. En la bibliografía especializada en las consecuencias que tuvo para los individuos su participación -activa o pasiva - en conflictos armados ( vid. por ejemplo, THORPE, 2003; BEYNEIX (2007); LEWIS (2007); GAITHER Y MURPHY, 2011) no abundan precisamente las alusiones a los infantiles y adolescentes. Como tendencia se observa que una amplia mayoría de los involucrados en tales situaciones son varones adultos, aunque no faltan casos en los que se describe la presencia de otras víctimas distintas, por lo que es complicado fijar un único perfil de referencia ( $v i d$. LARSEN, 1997: 120-151; 151 y BISHOP Y KNÜSEL, 2005: 207-209). Añádase otra cautela, y es que el no haber alcanzado la madurez biológica no implica necesariamente exclusión respecto a los 
sectores de la población implicados más habitualmente en acciones armadas (DAWSON et al., 2003; GAITHER Y MURPHY, 2011). En cambio, la localización de la herida en el cráneo sí sería decisiva para solventar nuestro problema. En efecto, las lesiones situadas en el frontal y en el parietal izquierdo son asimiladas normalmente al resultado de un golpe infligido por un agresor diestro en el curso de un combate o enfrentamiento cara a cara con la víctima, siendo, además, las más frecuentes en los contextos de contienda (LARSEN 1997: 157; WILLIAMSON, 2003: 114; KANZ Y GROSSCHMIDT, 2006: 215; DJURIC Y ROBERTS, 2006: 170-174; ROBERTS Y MANCHESTER, 2007: 108; LOVELL, 2008: 374-376).

En los tres individuos de Los Rompizales se ubican en el lateral derecho del cráneo y, más concretamente, en los número 3 y 4 , en su mitad posterior. Una localización que parece excluir que estas lesiones hubieran sido provocadas en un episodio como el descrito en el párrafo previo, pues se presentan precisamente en áreas craneales que no suelen quedar expuestas en este tipo de eventos. Por el contrario, hay que señalar, con las debidas reservas, que lesiones como las de Los Rompizales, identificadas en parietal derecho y occipital, suelen responder a una etiología muy diferente: golpes infligidos desde atrás por un diestro, muchas veces con la intención de causar un daño grave y en los que la víctima tiene escasas posibilidades de defenderse y aun de evitar el ataque (MAYS, 1998: 169-170; LARSEN, 1997: 157; ROBERTS Y MANCHESTER, 2007: 109).

De la magnitud de las lesiones descritas, en especial en los Individuos números 3 y 4 , que refleja la contundencia de los golpes, se infiere la intención de causar el mayor daño posible y, posiblemente, la muerte. Lo corrobora el patrón de fractura en esos dos individuos citados - en el $n^{\circ} 2$ es menos evidente, pero eso mismo lo indicarían la localización y la propagación de la fuerza hacia la cara- pues la ubicación anatómica y el aspecto de los hundimientos son indicativos de que los golpes en ambos casos debieron de realizarse desde la parte posterior, pues solo así se explicaría el modelo de irradiación de las fracturas y la particular morfología de las áreas deprimidas.

En este sentido, no puede dejar de llamarse la atención sobre la semejanza entre el aspecto de las fracturas del Individuo $n^{\circ} 4$ y las descritas por TA'ALA et al. (2006) en su análisis forense de traumas craneales de los campos de exterminio de los Jemeres Rojos. En ese trabajo se presenta un particular patrón de fractura resultante de ejecuciones en las que el verdugo se situaba tras cada víctima y, con un elemento contundente, le golpeaba en el occipital. Ello provocaba una intensa fracturación en la base del cráneo, siguiendo un modelo de afección muy claro (ibid., 1000), cuyas tres características esenciales -localización del impacto, ángulo de las fracturas y alcance de los daños-, que resultan distintivas frente a otros tipos de traumas craneales, se ven claramente en este individuo de Los Rompizales.

Finalmente, la ausencia de fracturas en el resto del esqueleto que pudieran interpretarse como resultado de intentos de defensa, impide también justificar las lesiones descritas en relación con un enfrentamiento armado (JIMÉNEZ-BROBEIL et al., 2014), y el hecho de que no se constaten otras heridas antiguas (cicatrizadas o en proceso de curación) indicaría que estos tres individuos no se hallaban en un marco de violencia habitual.
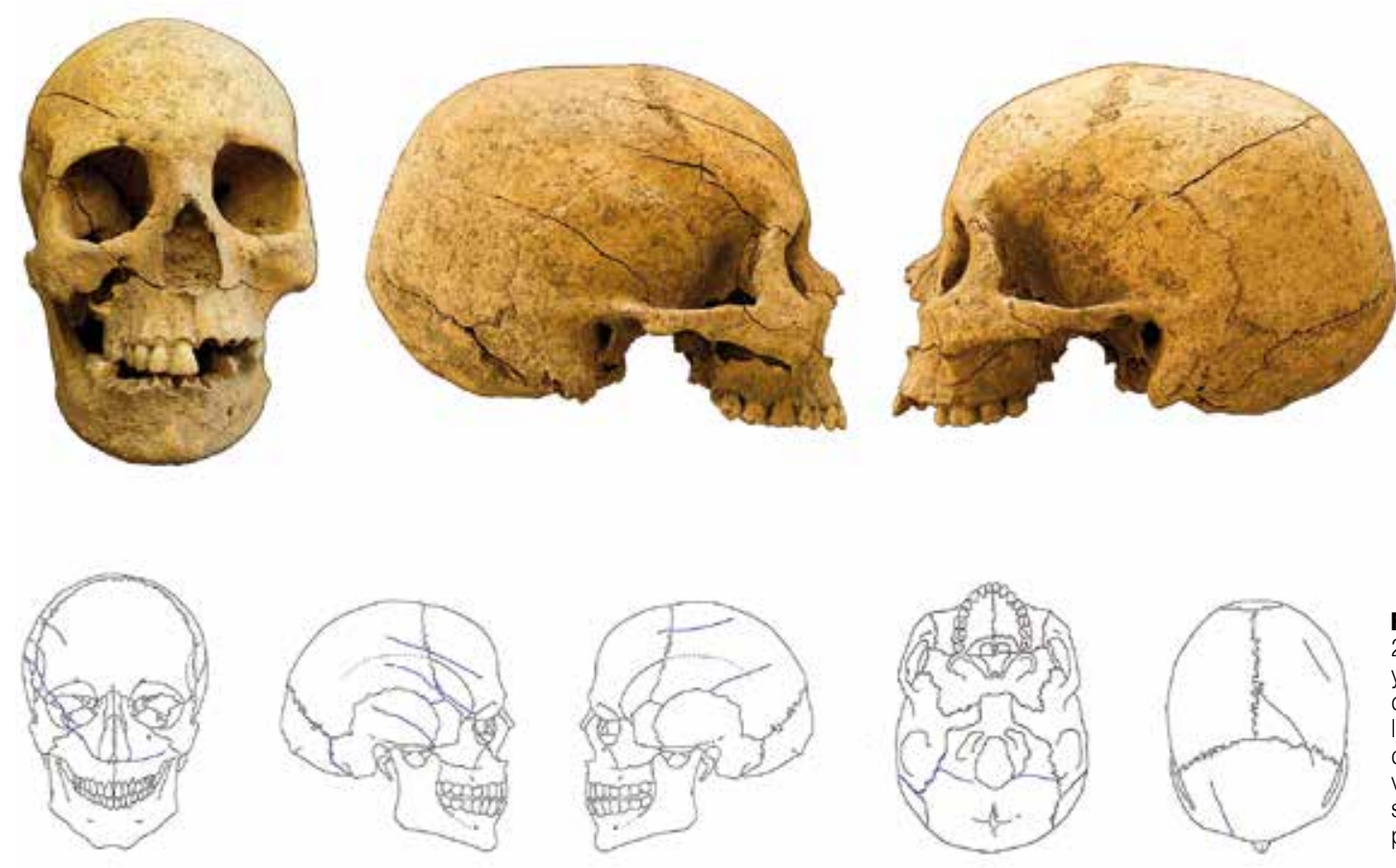

Fig. 9. Individuo $\mathrm{n}^{\circ}$ 2: Vistas del cráneo y croquis mostrando las fracturas en líneas paralelas / Individual no. 2: Skull views and sketches showing fractures in parallel lines. 

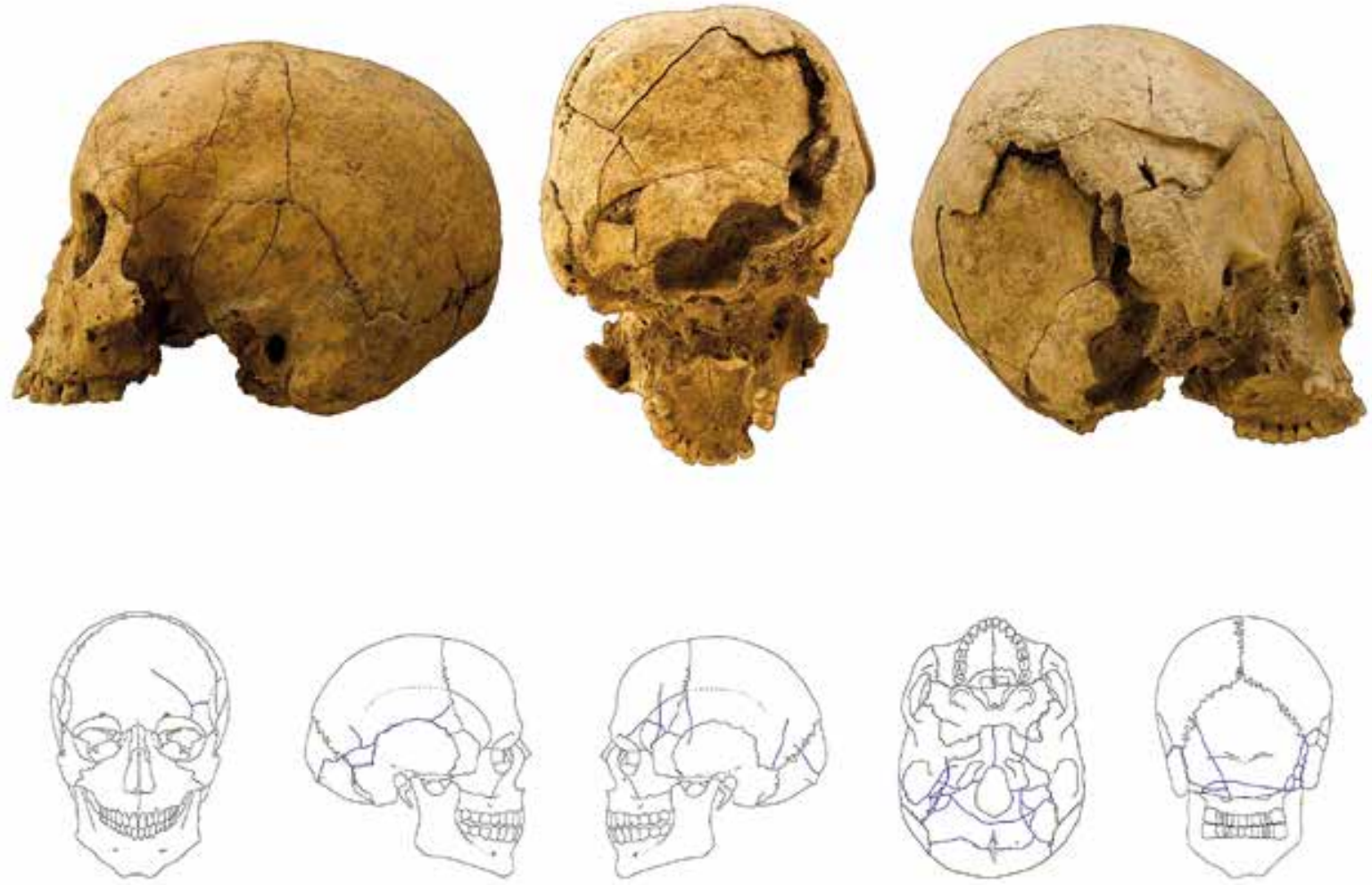

Fig. 10. Individuo $n^{\circ}$ 3: Vistas del cráneo y croquis mostrando las fracturas de tipo radial y concéntrico / Individual no. 3: Skull views and sketches showing fractures in a radial and concentric pattern.
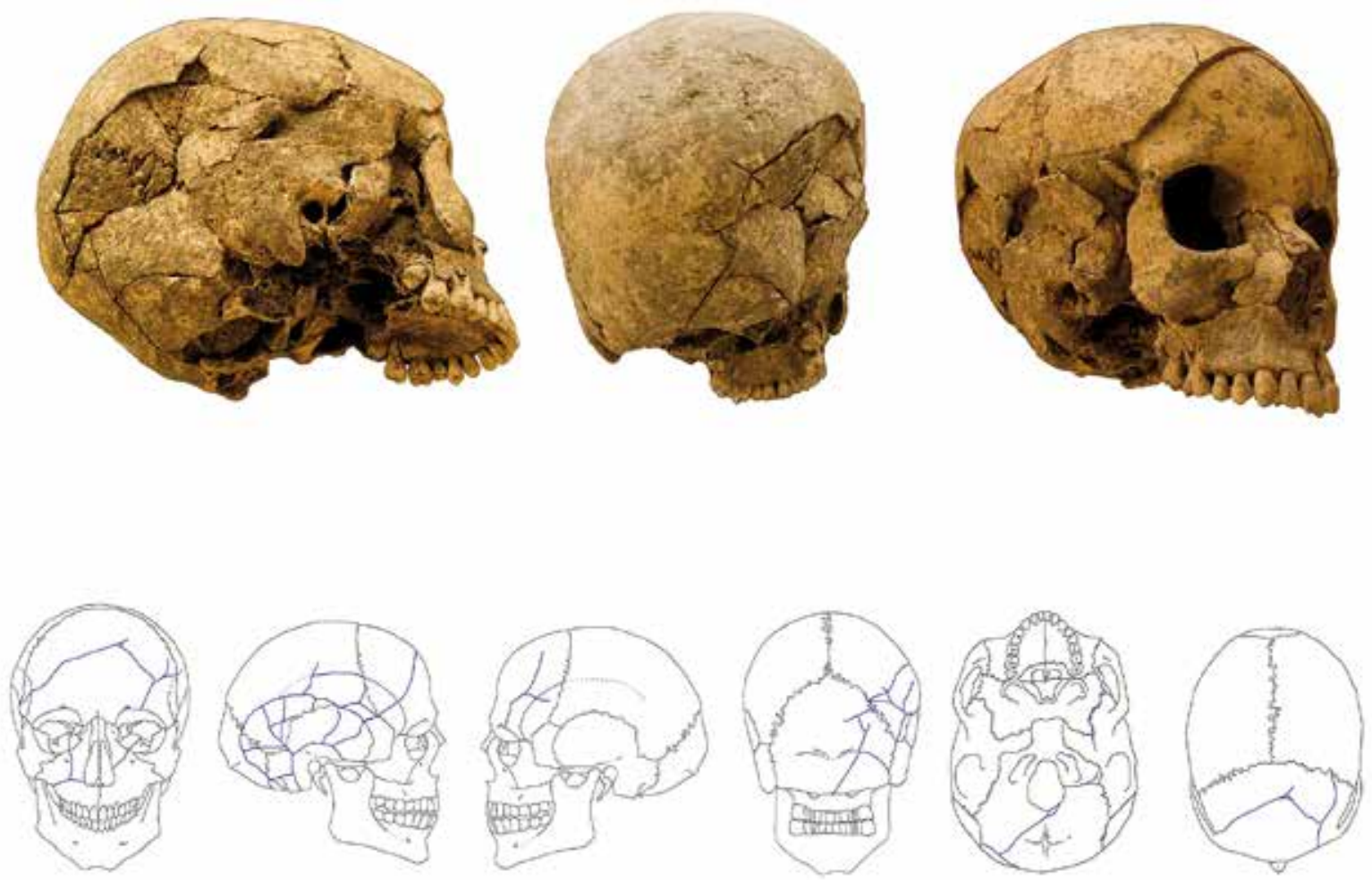

Fig. 11. Individuo $n^{\circ} 4$ : Vistas del cráneo y croquis mostrando las fracturas de tipo radial y concéntrico / Individual no. 4: Skull views and sketches showing fractures in a radial and concentric pattern. 


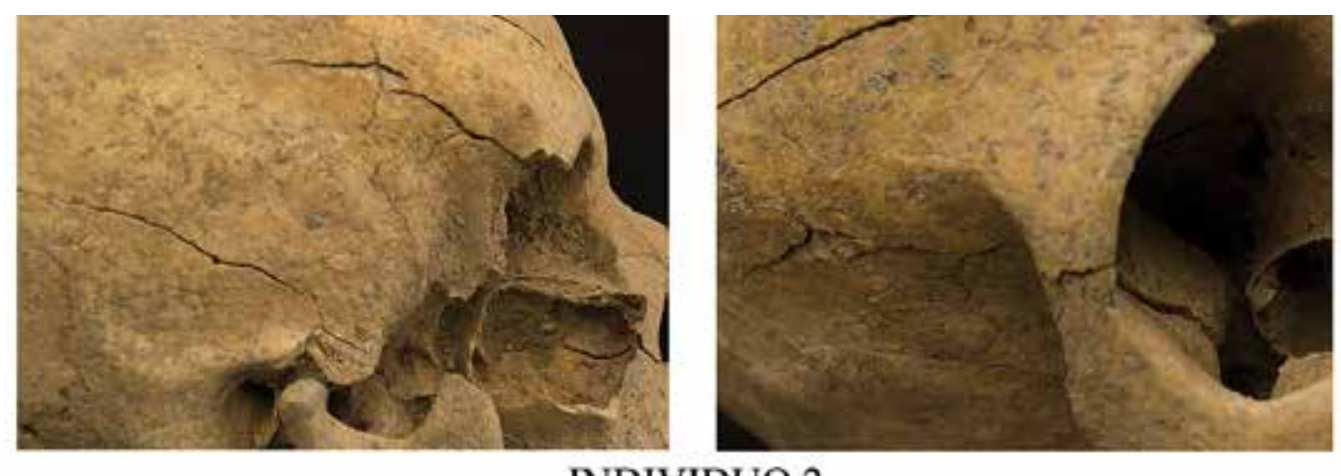

INDIVIDUO 2

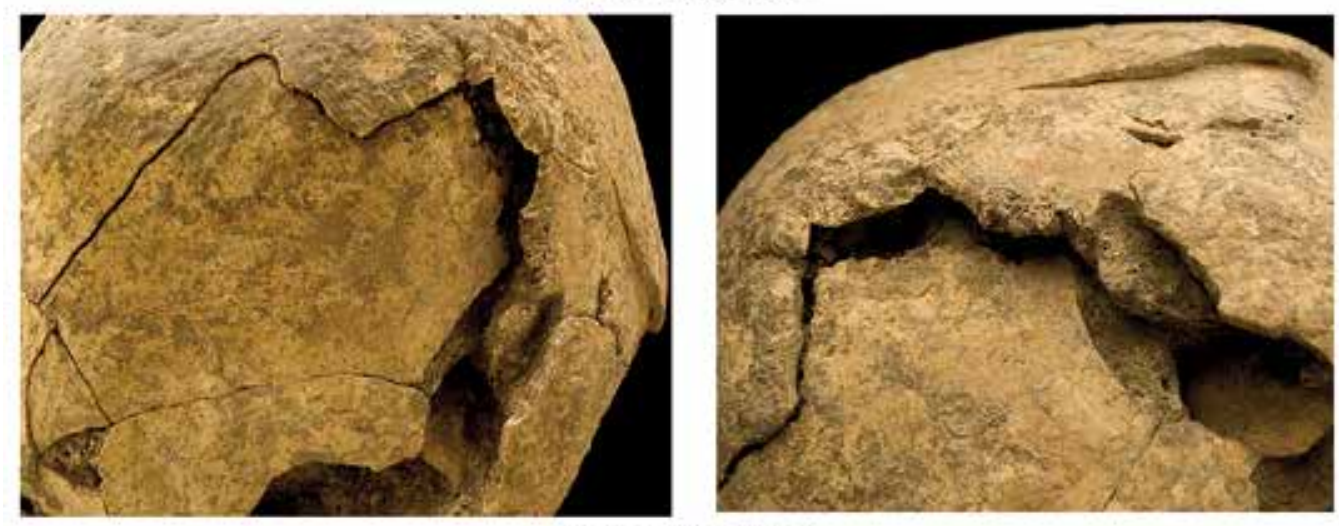

INDIVIDUO 3
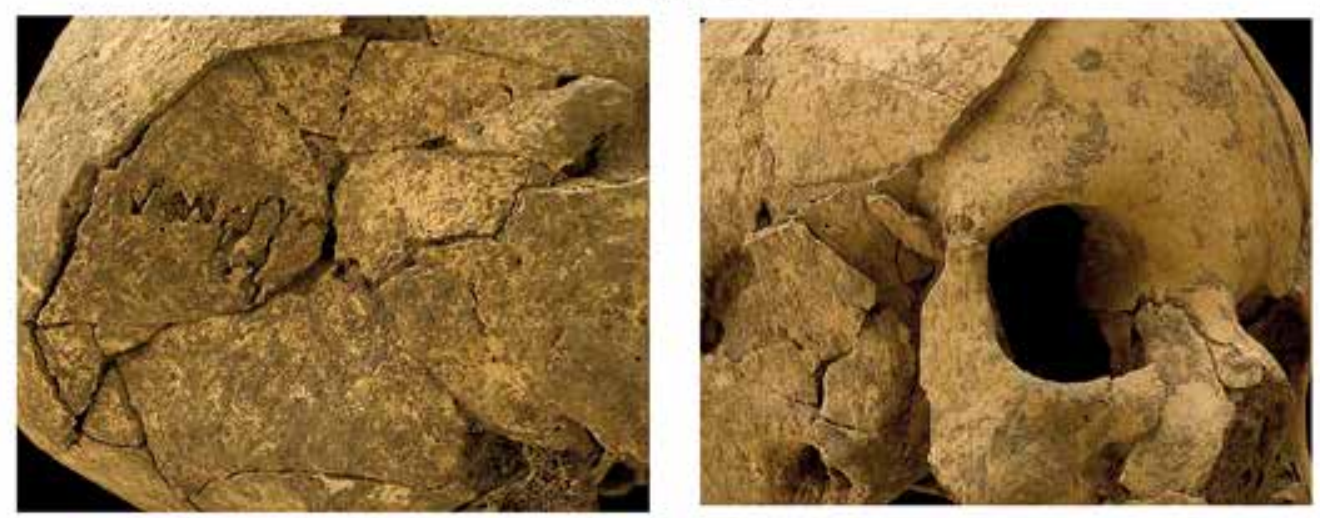

Fig. 12. Detalles de las lesiones traumáticas en los cráneos de los individuos 2, 3 y 4 / Details of traumatic injuries in the skulls of individuals

INDIVIDUO 4

\section{7e) Una lesión incisa en una vértebra}

Llamativamente, el Individuo $\mathrm{n}^{\circ} 1$ no presentaba en su cráneo ninguna afección equiparable a las descritas, lo que le confiere -junto a su posición central en el hoyo- una clara singularidad con respecto al trío con el que comparte depósito. Con todo, la evidencia bioantropológica indica que su muerte también tuvo lugar en un contexto de violencia.

En efecto, la undécima vértebra torácica de este sujeto presenta (Fig. 13) en la zona medial de la lámina derecha una lesión incisa perimortem que debió de ser provocada por el impacto violento de un objeto apuntado contra la parte posterior de la vértebra.
La naturaleza del objeto puede precisarse gracias a numerosos trabajos forenses sobre este tipo de heridas (HUMPHREY Y HUTCHINSON, 2001; CROFT Y FERLLINI, 2007; FERLLINI, 2012; LEWIS, 2007; THOMPSON E INGLIS, 2009; SHAW et al., 2011), siendo algo menos numerosas las referencias arqueológicas (p.ej., CRAIG et al., 2005; JIMÉNEZ-BROBEIL et al., 2014). En nuestro caso, el daño reconocible en el hueso, con una disposición ligeramente transversal al eje axial del cuerpo, presenta una longitud máxima de $7 \mathrm{~mm}$ en el exterior y unos $5 \mathrm{~mm}$ en el interior, así como una anchura que oscila entre $1 \mathrm{~mm}$ en su zona inferior y los $2 \mathrm{~mm}$ en la superior. Como es habitual en este tipo de heridas (THOMPSON E INGLIS, 2009: 130), el trauma afecta a la delgada pla- 

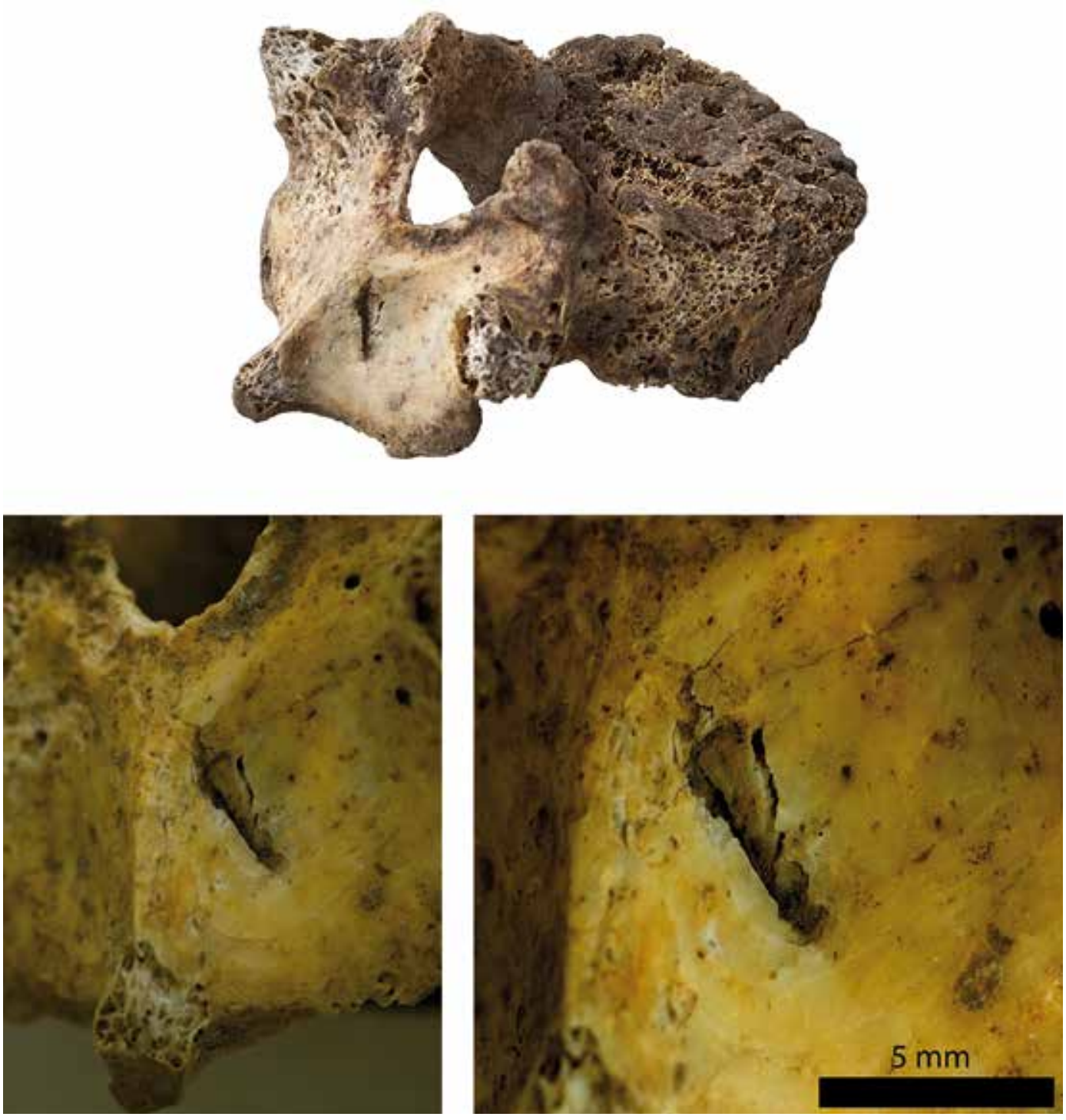

Fig. 13. La undécima vértebra torácica del Individuo $\mathrm{n}^{\circ} 1$ (arriba) y detalles de la lesión incisa en su zona medial (abajo) / Eleventh thoracic vertebra of the Individual no. 1 (top) and details of the incised lesion in the medial area (down).

ca de hueso compacto, provocando el hundimiento de parte del tejido óseo de los márgenes hacia el interior, lo que en este caso resulta especialmente perceptible en su flanco diestro, de suerte que una pequeña lámina de hueso compacto se clava en el trabecular. La afección al hueso esponjoso confiere una sección en $V$ a la fractura (KIMMERLE Y BARAYBAR, 2008: 268), con una profundidad de 1,5-2 mm en su zona central, que disminuye progresivamente a medida que avanza hacia sus extremos. Bajo lupa binocular, se aprecian muy bien en la parte más superficial del tejido compacto de la lámina tenues fracturas concéntricas que tienen su centro en la herida documentada.

Todos los elementos descritos llevan a plantear que tal herida perimortem debió de ser producida por el impacto violento de un elemento apuntado de doble filo y delgada sección, muy probablemente un puñal o similar (KIMMERLE Y BARAYBAR, 2008: 265-266; LEWIS, 2008). El alcance de la lesión, su localización y morfolo- gía y las alteraciones que genera sugieren que el daño fue provocado empleando gran fuerza (O'CALLAGHAN et al., 2009: 176-178), con una trayectoria de lateral a medial, si bien prácticamente perpendicular al cuerpo de la víctima. Así pues, la lesión descrita es compatible con una puñalada asestada por la espalda a este individuo, posiblemente por un agresor diestro situado tras él.

Atendiendo a su localización, la herida no merecería el calificativo de mortal, pues no afecta directamente a órganos vitales y, por ello, no habría provocado el fallecimiento inmediato de la víctima (SHKRUM Y RAMSAY, 2007: 386). En el mismo sentido, y a diferencia de otros casos (JIMÉNEZ-BROBEIL et al. 2014), no se identificaron otras afecciones óseas indicativas de ataques reiterados sobre el individuo que pudieran explicar completamente las causas de la muerte, aunque este dato negativo debe matizarse por el deficiente estado de conservación de algunas regiones esqueléticas, en especial las costillas. Más aún, no puede descartar- 
se que le hubiesen infligido otras heridas punzantes o cortantes que, sin dejar rastro alguno en el esqueleto, fueran realmente las responsables directas de la muerte del joven, cosa nada extraña, y bien conocida en la literatura forense (BANASR et al., 2003: 133).

Con todo, puede enmarcarse la puñalada por la espalda en un contexto de violencia intencional contra el individuo que a la postre ocuparía el centro del depósito de Los Rompizales. Quizás no fuese letal, pero es ilustrativa de las circunstancias que, como en los ejemplos anteriores, preceden a la conformación de este singular enterramiento.

\section{EL ENTERRAMIENTO Y SU DIMENSIÓN SOCIAL}

Establecido por el análisis bioarqueológico que este depósito mortuorio es el inequívoco resultado de una violencia, debe discutirse el tipo concreto de ésta para avanzar en la investigación social. No es tarea sencilla, dadas las muy variadas formas que reviste históricamente la violencia, como refleja el cuadro sistemático ofrecido por EISNER (2009: 43), y sobre todo por la inexistencia de fuentes complementarias, orales o escritas, que en la mayoría de los casos son imprescindibles para delimitar con precisión ciertas modalidades que a menudo se solapan entre sí (vid. también: HUGHES, 1991: 1-4; BIROCHEAU et al., 1999: 390).

En pura teoría, un enterramiento que resulta de la muerte coincidente de varios individuos podría explicarse sencillamente en relación con algún incidente de pequeña escala — fallecimiento accidental de unas personas asfixiadas, ahogadas, intoxicadas, etc.- o con procesos de mayor alcance como epidemias o situaciones de conflicto - caídos en combate, y, sobre todo, víctimas de una masacre, hoy muy bien tipificadas ( vid. GUILAINE Y ZAMMIT, 2001; BUIKSTRA Y ROBERTS, 2012; ERDAL, 2012)—, pero en el caso de Los Rompizales el modo de enterramiento, el tipo de lesiones observadas y el peculiar perfil demográfico parecen excluir unos y otros supuestos, y más aún la posibilidad de que se trate del resultado de un mero episodio de violencia interpersonal como una pelea juvenil. Por contra, la interpretación debe orientarse, entrando en un terreno bien diferente, hacia otras formas de muerte violenta que por su fuerte ritualización revelan su carácter de mecanismos de la vida social.

En efecto, hay situaciones —si no universales, sí muy generalizadas, lamentablemente- en las que matar a seres humanos no se considera asesinato, sino más bien algo necesario en relación con el orden social vigente. De las diversas formas de homicidio socialmente aprobado, algunas tienen un carácter específicamente religioso: son los sacrificios, consistentes, en esencia, en dar muerte a una persona cuya vida se ofrece a algún ente sobrenatural, con fines propiciatorios, expiatorios, etc. Otras veces son netamente penales, es decir, suponen el castigo máximo para determinadas conductas especialmente reprobables. En estos casos se habla de ejecución, y normalmente la muerte de esos criminales se produce con un alto de grado de ritualización y de forma notoria, para recalcar su carácter ejemplarizante, disuasorio. Finalmente, no deben olvidarse otras formas, las más chocantes desde nuestra visión actual, de carácter "preventivo", que consisten en la eliminación de individuos "anómalos" en los que se ve un peligro potencial para toda la comunidad: así, son vistos como una amenaza los nacidos en determinadas condiciones o con ciertas características (por ejemplo, gemelos, o estadios intersexuales, o todavía hoy los albinos en África); o los individuos que manifiestan determinadas conductas ("desórdenes mentales") o ciertas afecciones (epilepsia, lepra, etc.).

Esta heterogeneidad lastra la investigación arqueológica, que difícilmente podrá distinguir si la finalidad de la muerte era religiosa, penal o preventiva. Diversos trabajos insisten en el carácter equívoco del registro arqueológico y la consiguiente dificultad de deslindar sacrificios y ejecuciones, por ejemplo el de KNÜSEL (2005: 61) desde la bioarqueología; el de GREEN (1998) sobre la Edad del Hierro europea, donde se refiere a la fine line que separa sacrificio y ejecución, insistiendo en la necesidad de complementar críticamente datos arqueológicos y fuentes escritas; o el de ALFAYÉ (2008) sobre la Iberia prerromana, con resultados incontestables acerca de sacrificios de animales... y muy discutibles los de seres humanos.

Por otra parte, frente a las categorías excluyentes, la investigación histórica apunta hacia realidades más complejas, como la frecuente impregnación religiosa de lo que consideraríamos ejecuciones penales, o incluso del tercer grupo: por ejemplo, en Roma, ciertas penas de muerte eran dictadas en contexto religioso, diluyéndose la distinción entre ejecución y sacrificio. Así sucedía en casos de conductas transgresoras, como la de las vestales incestuosas, o anomalías físicas, como las criaturas hermafroditas, que -como refiere Tito Livioeran arrojadas vivas al mar (VAN HAEPEREN, 2004).

Asumiendo tales dificultades, exploraremos la posible correspondencia del caso de Los Rompizales con las tres formas antropológica e históricamente mejor documentadas de homicidio socialmente sancionado, esto es, sacrificios, 'muertes de acompañamiento' y ejecuciones.

\section{8a) Sacrificios humanos}

En el caso de los sacrificios humanos, las víctimas suelen ser seleccionadas por criterios relativos a la edad o la condición personal, por ejemplo, niños, jóvenes doncellas, prisioneros de guerra, etc., y arqueológicamente suele haber indicios como lesiones en el esqueleto, objetos empleados para degollar, ahorcar, etc., o algún tratamiento especial del cuerpo (p. ej., decapitación o descuartizamiento), sin olvidar alguna singularidad en cuanto al lugar de realización y su arquitectura, estructuras para recogida de sangre, etc. (vid. ALBERT et al., 2005; BENSON Y COOK, 2001, cap. 8) 
Para nuestro propósito comparativo interesan no tanto los inequívocos casos pertenecientes a altas culturas, sino los de otras de menor escala y por ello más aptas para el cotejo. De aquéllas, muchos casos se ven asegurados por la convergencia de fuentes históricas y arqueológicas. Así, en el Imperio Incaico se documenta la existencia de sacrificios de adolescentes de ambos sexos, hijos e hijas de dirigentes locales, así como de otros entregados como tributo por las comunidades subordinadas, informaciones que parecen haber encontrado recientemente correspondencia arqueológica (WILSON et al., 2007). Pero, frente a la tentación de ver en Los Rompizales un caso semejante, de adolescentes de uno y otro sexo, procedentes de comunidades distintas, raptados o entregados para ser objeto de sacrificio, hay que destacar las enormes diferencias con respecto al caso incaico: allá, en efecto, y dejando aparte el marco estatal, deben citarse la presencia de ofrendas y de ajuares indicativos del elevado estatus de las víctimas, y la tipología de los sitios de aparición, santuarios emplazados en cumbres eminentes. Otra referencia insoslayable sería la suministrada por TUNG Y KNUDSON (2010), en cuyo estudio de un conjunto de cráneos infantiles de Conchopata — un yacimiento del imperio preincaico de Huari-, los resultados de los análisis isotópicos indican que no son niños de origen local y sugieren que podían haber sido capturados en otras comunidades para ser sacrificados. Pero también en este caso, insistimos, el contexto sacrificial es inequívoco, a juzgar por las estructuras arquitectónicas y el acompañamiento cerámico y de animales también sacrificados; además, la iconografía cerámica refleja deidades recibiendo cabezas-trofeo.

En cambio, en sociedades menos complejas, la interpretación disminuye en seguridad. Así, se podría invocar el carácter sacrificial que — no sin controversiase propuso para algunas muertes violentas reconocidas en el complejo de Stonehenge: aquí, basándose en los ajuares y en la ubicación algún autor lo sostiene para la del considerado hijo del 'Arquero de Amesbury', producida supuestamente por un flechazo en el corazón y que constituiría un sacrificio refundacional; o la de la niña de 3 años con el cráneo partido en dos por un hachazo y enterrada en el centro del Woodhenge, en un sacrificio fundacional más antiguo. (vid. CASTLEDEN 2004: 125-6 y 220-2). Más próximo geográficamente, consignamos el yacimiento calcolítico de Los Cercados (Mucientes, Valladolid), donde tres cráneos femeninos con signos de violencia (GARCÍA BARRIOS ,2007) que citábamos en relación con la violencia de género, han sido considerados en relación con un sacrificio de índole regenerativa (Ibid: 52-53; DELIBES Y HERRÁN, 2007: 175-177), siendo el argumento decisivo la asociación de las calotas femeninas con cráneos de perro y cerdo, una cuerna de ciervo, una figurita zoomorfa de barro, un vaso caliciforme y dos vasos de cerámica simbólica con motivos oculados.
En el caso de Los Rompizales, ningún indicio seguro puede aportarse, salvo la selección por edades.

A decir verdad, la interpretación como sacrificio deja casi siempre cabos sueltos, y en la mayoría de las ocasiones cabría otra alternativa. Así, por ejemplo, en el yacimiento de Arslantepe, del Bronce Antiguo de Anatolia (SCHMIDT-SCHULTZ et al., 2001), un individuo con rico ajuar, compuesto por armas, adornos y joyas - se alude a una "tumba real", o de un "alto dignatario" - fue enterrado en una cista, sobre cuya cubierta se colocaron los cadáveres de cuatro adolescentes, un chico y una chica también con ajuares valiosos, y dos chicas, supuestamente de rango inferior por carecer de ajuar. Estos cuatro jóvenes pudieran haber sido objeto de muerte violenta - parece haber signos traumáticos en los tres esqueletos femeninos-y pertenecen con el personaje enterrado en la cista a un único evento ceremonial. Aunque se interpreta como asesinato o algún tipo de sacrificio (ibid.: 129) creemos posible encuadrarlo en otro tipo funerario mucho más preciso, el de las denominadas muertes de acompañamiento.

\section{8b) Muerte de acompañamiento}

TESTART (2004) ha estudiado en detalle esta modalidad fuertemente ritualizada, en la que señala como elemento esencial su relación con la dependencia personal -un fenómeno muy característico de civilizaciones relativamente sencillas, con formas estatales todavía carentes de verdadero aparato administrativosiendo difícil demostrar su existencia sin contar con fuentes escritas $u$ orales ${ }^{4}$. No obstante, en el registro arqueológico hay algunos rasgos que permiten reconocer una sepultura de acompañamiento, sobre todo el carácter asimétrico jerárquico, es decir, que un individuo no solo contrasta con otro(s) en cuanto a su ubicación, disposición, etc., sino que descuella también socialmente.

Revisten especial interés para la Prehistoria ciertos casos documentados por historiadores y etnógrafos en sociedades de menor escala, en las cuales los enterramientos no alcanzan el porte ni el lujo de las manifestaciones mesopotámicas, y que se relacionan con la esclavitud, generalmente de prisioneros de guerra a los que se daba muerte para que acompañasen a su amo (ibid: chap. 3). De este modo, en diversas tumbas múltiples del Neolítico Reciente -especialmente del Chassense, pero que parecen formar parte de un fenómeno más amplio, extendido desde el valle del Ródano hasta Centroeuropa - se ha reiterado la asimetría entre un individuo que desempeña el papel destacado, en perfecto decúbito lateral, y los que lo acompañan, arrojados sin contemplaciones, interpretados como esclavos (TESTART et al., 2010).

\footnotetext{
${ }^{4}$ En el ámbito ibérico se ha apuntado en algún caso (OLIVER FOIX, 2004: 402-4) la posibilidad de un acompañamiento de este tipo, que vendría a encajar con la conocida institución de la devotio descrita en las fuentes literarias.
} 
Volviendo al caso que nos ocupa, tampoco parece que el enterramiento de Los Rompizales encaje en tales supuestos, pues aunque se cumple la condición básica del contraste —es evidente la centralidad del Individuo $n^{\circ} 1$, al que además se le negó la colocación flexionada-, difícilmente puede considerarse que hay superioridad social sobre los tres restantes; por el contrario, este individuo puesto sin ningún miramiento, ¿no suscita antes que una impresión de privilegio, la de un especial rechazo? Un primus inter parias, podría decirse. La balanza parece inclinarse en definitiva hacia la tercera posibilidad, la de una ejecución, sin duda ritualizada, pero no cargada de contenido sacro ni de jerarquía social.

\section{8c) La ejecución}

Afrontar este tipo de conducta desde el terreno arqueológico no es una tarea sencilla, como ejemplifica el trabajo monográfico de OLIVER FOIX (2004): en su repaso de posibles indicios de este tipo de muertes en el mundo ibérico, lo cierto es que salvo los casos de lapidaciones - que necesitarían una revisión especializada de las fracturas craneales-y decapitaciones, apenas hay evidencia firme. Pero alguna vez es el propio registro arqueológico el que, aun faltando evidencia osteológica de la forma de muerte, permite argumentar que hubo ejecuciones: así, en el caso de cinco individuos inhumados en época tardorromana en Pamplona, se ha concluido que fueron ejecutados, porque los cinco fueron enterrados conjuntamente en una fosa, uno de ellos con las manos atadas a la espalda (MIGUEL IBÁÑEZ et al. 2007).

Asumidas las dificultades, convendría partir del planteamiento inverso, el del conocimiento procedente de las fuentes históricas, etnográficas, etc. Como se ha dicho, muchas sociedades a lo largo de la historia han venido aceptando la eliminación física de seres humanos, en ocasiones por motivos tan aleatorios como la existencia de anomalías físicas, psicológicas, etc., y sobre todo como máxima pena para conductas contrarias a las normas o leyes. Por ello, conviene apurar la búsqueda de rasgos personales o conductas que, por haber sido considerados como manifestaciones de desviación, pudieran haber desencadenado el homicidio socialmente legitimado, y a partir de ahí abordar su posible detección arqueológica.

Hay casos de anomalía con resultado letal bien conocidos en la literatura especializada, como son los de personas afectadas por lepra (BREDERO, 1994: 296) o epilepsia (LUCERO Y GIBBS, 2007: 45-46), siendo especialmente interesante para nuestro caso la relación a menudo advertida entre tales afecciones y una colocación funeraria intrigante como es el decúbito prono. En efecto, los esqueletos en procúbito a veces se explican suponiendo que los individuos así enterrados eran percibidos como anormales a causa de una discapacidad física o desorden mental, habiéndose recogido algunos posibles ejemplos (BAIN, 1998: 1054; ALFAYÉ,
2009: 208-210). Obviamente, establecer un diagnóstico correcto es difícil, pero no imposible, como ilustra una sepultura ateniense de la Edad del Hierro, cuyo esqueleto revela un trauma craneal y vertebral, severo pero no mortal, que podría haber dado origen a un daño neurológico o a una epilepsia post-traumática, y en definitiva, a una percepción social negativa y a una tumba anómala (LITTLE Y PAPADOPOULOS, 1998).

No habiéndose hallado en Los Rompizales indicadores esqueléticos de esos u otros tipos de "anomalías", deben examinarse las otras modalidades de ejecución que, además, están mucho mejor avaladas arqueológicamente.

Ciertamente, la denominada pena de muerte es casi universal, estando bien documentada ya en las civilizaciones antiguas, pero también en la bibliografía antropológica, y con una enorme variedad, incluyéndose entre sus variantes la llamada venganza de sangre, que tampoco parece convenir a nuestro caso: aunque no puede descartarse rotundamente que los cuatro individuos de Los Rompizales fuesen miembros de una comunidad ajena a los que se dio muerte en aplicación de una venganza de sangre, la cuidadosa y premeditada disposición de los cuerpos en el enterramiento no parece apoyarlo.

En general, la pena de muerte tenía en las diversas sociedades una aplicación bastante restringida. Como simple botón de muestra, entre los Bantúes se reservaba para conductas consideradas de la máxima gravedad como brujería, traición, asesinato o incesto (MYBURGH, 1974: 286) y los culpables eran ejecutados por procedimientos terribles (apuñalados, apaleados, empalados, lapidados, etc.) (ibid.: 299).

De esas conductas tenidas por desviadas destaca por su universalidad la brujería, un ámbito en el que además se ha documentado la eliminación de niños y jóvenes: son frecuentísimas las menciones históricas a la ejecución de personas, incluyendo individuos infantiles o adolescentes, bajo la acusación de prácticas hechiceras, entremezcladas real o supuestamente con conductas sexuales irregulares. Se tienen incluso noticias relativamente recientes de la ejecución de niños acusados de brujería entre los indígenas arawak de la Amazonía peruana, siempre con gran violencia - aporreados, estrangulados, apedreados, quemados vivos, etc.- justificándose esa ferocidad porque eran considerados como seres no humanos (SANTOS-GRANERO, 2004: 279).

En el terreno propiamente arqueológico, no faltan tampoco las referencias interesantes. Por ejemplo, ciertos hallazgos en torno al castillo de Oxford, con más de sesenta enterramientos de individuos ejecutados en la Edad Moderna, incluyendo un adolescente de unos 12-15 años, estrangulado y colocado boca abajo, que podría haber sido ejecutado por brujería, como se sospecha para las mujeres presentes en el conjunto, también ahorcadas (KEYS, 2004: 12; TARLOW, 2011: 76); o 
en Barbados la identificación, con apoyo etnohistórico, de un enterramiento en procúbito y sin ajuar de un esclavo de origen africano, al que presumiblemente se dio muerte por considerarlo hechicero (HANDLER, 1996). Sobre todo, recuérdense las numerosas inhumaciones múltiples del período Anasazi del Suroeste de Norteamérica, cuyos restos fracturados, descarnados, etc., venían siendo explicados mediante el canibalismo, pero en realidad, serían depósitos especiales relacionados con la persecución de la brujería (DARLING, 1998). En apoyo del registro arqueológico, las observaciones etnohistóricas relativas a Navajos y Pueblo reflejan insistentemente la creencia en que la brujería era un mal hereditario, por lo que debía ser extirpado mediante la eliminación - a menudo a garrotazos- de familias enteras, lo que suponía una enorme vulnerabilidad de los subadultos. Destaca la "terrible violencia" empleada en este tipo de ejecuciones, tan perfectamente ritualizadas que algunos observadores las tenían por sacrificios (ibid:: 737-738). En la misma línea insisten OGILVIE y HILTON (2000), con nuevos hallazgos en la zona de Nuevo Méjico, también de inhumaciones masivas de individuos sometidos a muerte violenta y descuartizamiento.

Actualmente se considera que las personas acusadas de brujería son sancionadas para restaurar el orden social que supuestamente habrían quebrantado, empleando para ello castigos que pueden ir desde correctivos más o menos severos hasta la pena capital. Autores como TIESLER (2007: 19-20) o LUCERO Y GIBBS (2007: 46) han planteado que en estos casos más extremos, las maneras de matar y el tratamiento de los cuerpos deben entenderse también como un discurso destinado al resto de la población, ejemplarizante y disuasorio. Así las cosas, lo que destilan diversas fuentes, etnográficas, históricas y arqueológicas, podría proporcionar un encuadre aplicable — solo de forma tentativa - al caso de Los Rompizales: por ejemplo, teniendo en cuenta la condición de los enterrados - tres chicos y una chica aparentemente sanos y sin malformaciones- y la razonable suposición de que algo muy grave les acarreó la pena máxima, ¿no se podría aventurar la posibilidad de que hubieran llevado a cabo actos de hechicería o bien que hubiesen practicado una sexualidad transgresora, o ambas cosas? Tal suposición, aunque plausible, no puede ser debidamente contrastada, por lo que habrá que concluir, de forma menos arriesgada, que estamos ante una situación terrible que se materializó en una auténtica escenografía mortuoria. Desde luego, no parece que este enterramiento pueda ser despachado como el único caso comparable que conocemos, el de los cuatro individuos de 8, 9, 10 y 15 años y sexo no determinado, sin "lesiones de defensa", enterrados —unos de ello en procúbito- en un foso del yacimiento anglo-sajón de Fordham (Inglaterra): según REYNOLDS (2009: 46) se habría dado muerte a una "banda rebelde" de niños.

En suma, en Los Rompizales se detecta un proceso altamente ritualizado, todo un programa de actos de- mostrativos que se desarrollan siguiendo una secuencia pautada y con una función esencialmente comunicativa. Quizá sea en estos rasgos donde también se explique en última instancia este depósito, pues tanto la muerte sufrida por estas personas como el modo en el que fueron dispuestas pueden ser leídos en esos términos: las distintas y contundentes fórmulas de violencia empleadas con los subadultos y su relación con el lugar que ocuparían cada uno de ellos en el hoyo, la organización del espacio inhumatorio, la premeditada disposición de los cadáveres, el modo en el que fueron cubiertos... son elementos que invitan a pensar en una "volonté flagrante de mis en scène" (BIROCHEAU et al., 1999: 390), una dramatización codificada, ritualizada, de la muerte y el entierro de estos jóvenes.

\section{CONSIDERACIONES FINALES}

El tipo de violencia constatado en los registros arqueológico y osteológico no corresponde, sin duda, a procesos bélicos o masacres, sino a un tipo muy distinto de 'culturally sanctioned ritual violence' (GAITHER, 2012: 71), sin que el análisis permita por ahora, asegurar una explicación en detalle de lo ocurrido en el sitio de Los Rompizales; además, como se ha visto, las fronteras entre sacrificio, acompañamiento no jerárquico y ejecución ritual son lábiles, y no menos frágiles las categorías culturales de anomalía o desviación. La ausencia de fuentes orales o escritas supone en estos casos un límite insalvable.

Como se ha indicado al principio de este trabajo, nuestra investigación se orienta —en el sentido propuesto por GRAMSCH Y MEIER (2013) - hacia la detección de acciones formalizadas y repetidas. Desde luego, en los diversos enterramientos en hoyo del grupo Cogotas I, y ahora también en Los Rompizales, se constata reiteradamente una serie de rasgos: a) la integración en el espacio habitacional; b) no se creó un espacio ceremonial ad hoc; c) se aprovechó un hoyo preexistente - probablemente un silo abandonadoque ya había empezado a colmatarse; d) los cuerpos fueron colocados sobre todo contra la pared del hoyo; e) hay una disposición planificada de los cuerpos, con una marcada tendencia al decúbito lateral según sexo; f) la absoluta carencia de cualquier elemento de acompañamiento, ni individual ni común. Pero en el entierro de Los Rompizales hay ciertos rasgos específicos cuya repetición deberá comprobarse en nuevos hallazgos: g) la insistencia en poner los rostros de los enterrados contra el suelo; y h) la sensación de crueldad o de falta de humanidad en el tratamiento que se dispensó a los muertos, particularmente con el $\mathrm{n}^{\circ} 1$, pero también con $n^{\circ} 4$, depositado de mala manera al no haberse retirado la gran piedra sobre la que quedó la mitad inferior de su cuerpo (Fig. 14). Todo ello, llevado a cabo —quizá por más de un individuo- meticulosamente y no con ocultamiento o en un paraje apartado, sino en el propio sitio de habitación, sugiere probablemente el carácter público del acto, que se orientaría así en el sentido que 


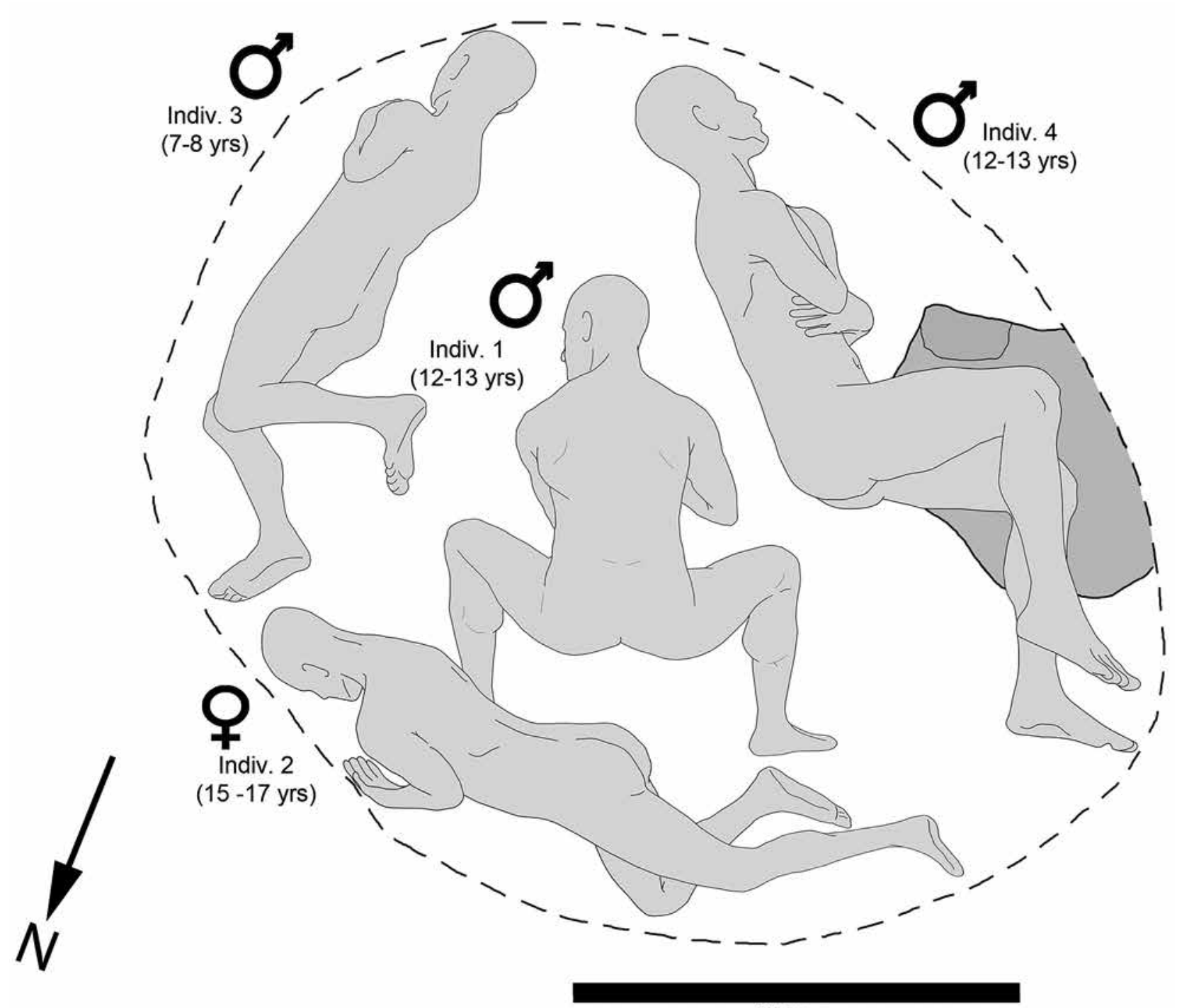

\section{$0,5 \mathrm{~m}$}

Fig. 14. Reconstrucción mostrando el emplazamiento aproximado de los cuerpos en el enterramiento en hoyo. / Reconstruction showing the approximate placement of the bodies within the pit burial.

FOUCAULT (1975: 61) desvela en las ejecuciones anteriores al siglo XIX: los espectadores, viéndolo todo con sus propios ojos, sentían temor, se convertían en testigos y en cierta manera participaban en el castigo.

Nos hallaríamos, en definitiva, ante una representación "teatral" de fuerte potencial intimidatorio, un momento de la vida comunitaria de poderosa eficacia aleccionadora acerca de los límites permisibles de la conducta y un importante mecanismo de carácter coercitivo orientado a la creación y el mantenimiento del orden social. En tal sentido, si la hechicería hubiera sido el desencadenante de la muerte violenta de los cuatro subadultos de Los Rompizales, estaríamos ante un drama social, concepto de la Antropología Política acuñado por V. Turner para denominar a los episodios de tensión relacionados con la resolución de fenómenos de escisión social. Para este autor las acusaciones de bruje- ría serían en realidad indicadores superficiales de una conflictividad subyacente por el poder y la tierra. (cit. in STEWART Y STRATHERN, 2004: 4).

En la estrategia metodológica que hemos desplegado se ha prestado atención al conjunto bioarqueológico, a la naturaleza de las lesiones y posibles referencias etnográficas e históricas, pero para la interpretación de los tipos de violencia sería importante, como se ha dicho, contar también con otra información contextual, la proporcionada por ciertos elementos como armas, estructuras defensivas u otros indicadores bélicos. En este sentido, aunque Cogotas I necesita todavía mucha más investigación, parece un ámbito relativamente "pacífico", en comparación con otras culturas de la Edad del Bronce. En efecto, a diferencia de aquellas como la Micénica en las que hay clara evidencia de actividades bélicas, u otras como la 
Argárica, caracterizada por la violencia estructural de una minoría sobre la mayoría de la población (LULL Y $\mathrm{RISCH}, 1995)$, en Cogotas I hasta el presente no hay ningún testimonio de masacres ni de conflicto intergrupal; las armas, no muy numerosas, están ausentes del registro funerario, formando parte más bien de depósitos simbólicos, y los escasos recintos detectados en Cogotas I Formativo, más que fortificaciones debieron de ser estructuras relacionables con ceremonias de agregación (RODRÍGUEZ MARCOS Y MORAL DEL HOYO, 2007). Más aún, si algunos autores (p.ej., DELIBES et al., 1999: 56-57) advierten en Cogotas I algunos indicios de jerarquización -las citadas armas y algunas joyas áureas, especialmente-, otros proponen que estamos más bien ante una sociedad segmentaria, articulada especialmente sobre el linaje (ARNÁIZ ALONSO Y MONTERO GUTIÉRREZ, 2012).

Sobre este controvertido marco se añade ahora la novedosa evidencia de un tipo de violencia de índole no bélica. En este caso probablemente podría hablarse también de violencia como estrategia política, como ejercicio de dominación y control social, de demostración de poder, de construcción de ideología (RALPH, 2013: 2-6). Además, este caso cuádruple, el primero hallado entre los enterramientos primarios de Cogotas I, viene a reforzar las consideraciones hace poco expuestas acerca de la llamativa frecuencia de las sepulturas triples, que apuntaban en el sentido de que todas las sepulturas en hoyo de esta cultura fueran excepcionales (ESPARZA et al., 2012a: 294 y 299-300).

Por último, el enterramiento de Los Rompizales constituiría también un nuevo aval para la hipótesis según la cual si el procedimiento funerario normativo del grupo Cogotas I habría sido la exposición de cadáveres, los enterrados en hoyos serían aquellos individuos fenecidos bajo diversas variantes de mala muerte (ESPARZA et al., 2012b). La muerte de los cuatro individuos de Los Rompizales es probablemente la peor de las hasta ahora conocidas.

\section{AGRADECIMIENTOS}

Queremos agradecer al Ministerio de Economía y Competitividad por el apoyo financiero de la presente investigación (proyectos HAR2009-10105 y HAR201341851-P); a la Junta de Castilla y León, por el apoyo de nuestro trabajo museístico. Agradecemos al Prof. Germán Delibes de Castro (Universidad de Valladolid) su inestimable ayuda; al Prof. Tomasz Goslar (Poznan Radiocarbon Laboratory) por las dataciones AMS; a D. Ángel Rodríguez por el mapa y el dibujo de cerámica; a los anónimos revisores del manuscrito. Estamos especialmente reconocidos a nuestros amigos $\mathrm{M}^{\mathrm{a}}$ Eugenia Delgado Arceo y Luis Villanueva Martín, de Antequem Arqueología y Medio Ambiente SL, que muy generosamente nos han suministrado todo tipo de información sobre la excavación en Los Rompizales y los restos humanos.

\section{BIBLIOGRAFIA}

\author{
ABARQUERO MORAS, F.J.
}

2005 Cogotas I: la difusión de un tipo cerámico durante la Edad del Bronce. Junta de Castilla y León. Valladolid.

ABARQUERO-MORAS, F.J., BLANCO-GONZÁLEZ, A., ESPARZA-ARROYO, A. \& RODRÍGUEZ-MARCOS, J. A.

2013 The Central Iberian Meseta at the time of the Thera eruption: an overview, en MELLER, H. BERTEMES, F., BORK, H. R. \& RISCH, R. (Hrsg.): 1600 - Kultureller Umbruch im Schatten des Thera-Ausbruchs?. 315-326. Tagungen des Landesmuseums für Vorgeschichte Halle, 9. Halle.

ALBERT, J.-P., CRUBEZY, E. \& MIDANT-REYNES, B.,

2005 L'archéologie du sacrifice humain, Problèmes et hypothèses, en ALBERT, J. P. \& MIDANT-REYNES, B. (Eds, ) Le sacrifice humain en Égypte ancienne et ailleurs. 2032. Soleb. Paris.

ALFAYÉ VILLA, S.

2008 Ritos de sangre. Sacrificios cruentos en los ámbitos celtibérico y vacceo, en BURILLO MOZOTA, F. (Ed.) Ritos y mitos: VI Simposio sobre Celtiberos. 219-238. Centro de Estudios Darocenses. Daroca.

2009 Sit tibi terra gravis: magical-religious practices against restless dead in the Ancient World, en MARCO SIMÓN, F., PINA POLO, F. \& REMESAL RODRÍGUEZ, J. (Coords.). Formae mortis: el tránsito de la vida a la muerte en las sociedades antiguas. 181-216. Universidad de Barcelona. Barcelona.

\section{ANTEQUEM, S.L.}

2009 Informe final de la excavación arqueológica en el yacimiento 'Los Rompizales'. Proyecto constructivo Circunvalación de Burgos BU-30. Tramo Villalbilla de Burgos-Quintanadueñas (Provincia de Burgos). Informe Técnico depositado en el Servicio Territorial de Cultura (Junta de Castilla y León) de Burgos.

ARANDA JIMÉNEZ, G., MONTÓN SUBIAS, S. \& JIMÉNEZ BROBEIL, S. A

2009 Conflicting evidence? Weapons and skeletons in the Bronze Age of south-east Iberia. Antiquity 83(322), 1038-1051.

ARMIT, I., KNÜSSEL, C., ROBB, J. \& SCHULTING, R.

2007 Warfare and Violence in Prehistoric Europe: an Introduction. Journal of Conflict Archaeology 2, 1-11.

ARMENDARIZ, J. \& IRIGARAY, S.

1994 La arquitectura de la muerte. El hipogeo de Longar (Viana, Navarra), un sepulcro colectivo del 2500 a.C. Centro de Estudios Tierra-Estella. Estella.

\section{ARNÁIZ ALONSO, M.A. \& MONTERO GUTIÉRREZ, J.}

2011 Funerary expression and ideology in the Cogotas Culture settlements in the northern Meseta of the Iberian Peninsula, en MOORE, T. \& ARMADA, X.L. (Eds.), Atlantic Europe in the First Millennium BC: Crossing the Divide. 558-574. Oxford University Press. Oxford. 
BAIN, S.

1998 Excavation of a medieval cemetery at Holyrood Abbey, Edinburgh. Proceedings of the Society of Antiquaries of Scotland 128, 1047-1077.

BANASR, A., LORIN, G. \& DURIGON, M.

2003 Frequency of bone/cartilage lesion in stab and incised wounds fatalities. Forensic Science International 131(2), 131-133.

BARAY, L. \& BOULESTIN, B., (Eds.)

2010 Morts anormaux et sépultures bizarres : les dépôts humains en fosses circulaires ou en silos du Néolithique à l'âge du Fer. Éditions Universitaires de Dijon. Dijon.

BENSON, E.P., \& COOK, A.G.

2001 Ritual sacrifice in ancient Peru. University of Texas Press. Austin.

\section{BERRYMAN, H. \& JONES, S.}

1996 Applying forensic techniques to interpret cranial trauma fracture patterns in an archaeological specimen. International Journal of Osteoarchaeology 6, 2-9.

BEYNEIX, A.

2007 Réflexions sur les débuts de la guerre au Néolithique en Europe occidentale. L'Anthropologie 111, 79-95.

BILO, R., ROBBEN, S. \& VAN RIJN, R.

2010 Forensic aspects of pediatric fractures. Differentiating accidental trauma from child abuse. Springer. Heidelberg.

BIROCHEAU, P., CONVERTINI, F., CROS, J. P., DUDAY, H.\& LARGE, J. M.

1999 Fossé et sépultures du Néolithique récent aux Châtelliers du Vieil-Auzay (Vendée); aspects structuraux et anthropologiques. Bulletin de la Société préhistorique française 96(3), 375-390.

BISHOP, N. \& KNÜSEL, C.

2005 A palaeodemographic investigation of warfare in prehistory, en Parker Pearson \& Thorpe. 201-216.

BOTELLA, M., ALEMÁN, I. \& JIMÉNEZ, S.

2000 Los huesos humanos: manipulación y alteraciones. Edicions Bellaterra. Barcelona.

\section{BOYLSTON, A}

2000 Evidence for weapon-related trauma in british archaeological samples, en Cox \& Mays. 357-380.

BREDERO, A.H.,

1994 Christendom \& Christianity in the Middle Ages: The Relations Between Religion, Church, \& Society. W.B. Eerdmans. Grand Rapids.

BRONK RAMSEY, C.

2009 Bayesian analysis of radiocarbon dates. Radiocarbon 51(1), 337-360.
BUIKSTRA, J. \& ROBERTS, C.

2012 The Global History of Paleopathology: Pioners \& Prospects. Oxford University Press. Oxford.

BUIKSTRA, J. \& UBELAKER, D.

1994 Standards for data collection from human skeletal remains. Proceedings of a Seminar at the Field Museum of Natural History. Arkansas Archeological Survey (Research Series, 44). Fayetteville.

CALCE, S.E. \& ROGERS, T.L.

2007 Taphonomic Changes to Blunt Force Trauma: A Preliminary Study. Journal of Forensic Sciences 52(3), 519-527.

\section{CASTLEDEN, R.}

2004 The Making of Stonehenge. Routledge. London ( $2^{\mathrm{a}} \mathrm{ed}$.).

COX, M. \& MAYS, S. (Eds.)

2000 Human Osteology in archaeology and forensic science. Greenwich Medical Media Ltd. London.

CRAIG, R., KNÜSEL, C. \& CARR, G.

2005 Fragmentation, mutilation \& dismemberment: an interpretation of human remains on Iron Age sites, en PARKER PEARSON \& THORPE. 165-180.

CRAMER, K. \& GREEN, N.

2003 Child Abuse, en GREEN \& SWIONTKOWSKI. 705-725.

CROFT, A.M. \& FERLLINI, R.

2007 Macroscopic characteristics of screwdriver trauma. Journal of Forensic Sciences 52(6), 1243-1251.

CUNHA, E. \& PINHEIRO, J.

2005-2006 A linguagem das fracturas: a perspectiva da Antropologia Forense. Antropologia Portuguesa 2223, 223-243.

DARLING, J.A.

1998 Mass inhumation and the execution of witches in the American Southwest. American Anthropologist 100(3), 732-752.

DAWSON, L., LEVY, T. E. \& SMITH, P.

2003 Evidence of interpersonal violence at the Chalcolithic village of Shiqmim (Israel). International Journal of Osteoarchaeology 13(3), 115-119.

DELIBES DE CASTRO, G. \& HERRÁN MARTíNEZ, J. I.

2007 La Prehistoria. Diputación de Valladolid, Valladolid.

DELIBES DE CASTRO, G., FERNÁNDEZ MANZANO, J., FONTANEDA PÉREZ, E. \& ROVIRA LLORENS, S.

1999 Metalurgia de la Edad del Bronce en el piedemonte meridional de la Cordillera Cantábrica: la Colección Fontaneda. Junta de Castilla y León. Valladolid. 
DJURIĆ, M. P., ROBERTS, C. A., RAKOĆEVIĆ, Z. B., DJONIĆ, D. D. \& LEŠ́ĺ, A. R.

2006 Fractures in late medieval skeletal populations from Serbia. American Journal of Physical Anthropology 130(2), 167-178.

DUDAY, $\mathrm{H}$.

2005 L'archéothanatologie ou l'archéologie de la mort, en DUTOUR, O., HUBLIN, J.J. \& VANDERMEERSCH, B (Eds.), Objets et méthodes en paléoanthropologie. 153-207. Comité des Travaux Historiques et Scientifiques. Paris.

2009 The archaeology of the dead. Lectures in Archaeothanatology. Oxbow Books. Oxford.

DUDAY, H. \& GUILLON, M.

2006 Understanding the circumstances of descomposition when the body is skeletonized, en SCHMITT, A., CUNHA, E. \& PINHEIRO, J. (Eds.). Forensic Anthropology and Medicine : Complementary Sciences from Recovery to Cause of Death. 117-157. Humana Press Inc., Totowa.

DURAND, R.

2008 Donnés paléodémographiques et classes d'âge immatures: recrutement et gestion des enfants dans les espaces funéraires gallo-romains, en GUSI et al. 41-56.

EISNER, M

2009 Uses of Violence: An Examination of Some Cross-Cutting Issues. International Journal of Conflict and Violence 3(1), 40-59.

ERDAL, Ö. D.,

2012 A possible massacre at Early Bronze Age Titriş Höyük, Anatolia. International Journal of Osteoarchaeology 22 $1-21$.

ESPARZA, A., DELIBES, G., VELASCO, J. \& CRUZ, P. J.

2008 Historia de un golpe en la cabeza: sobre el enterramiento calcolítico del Hoyo 197 de "El Soto de Tovilla" (Tudela de Duero, Valladolid). Boletín del Seminario de Arte y Arqueología. Arqueología 74(1), 9-48.

ESPARZA ARROYO, A., VELASCO VÁZQUEZ, J. \& DELIBES DE CASTRO, G

2012a HUM 2005-00139: Planteamiento y primeros resultados de un proyecto de investigación sobre la muerte en Cogotas I, en RODRÍGUEZ MARCOS \& FERNÁNDEZ MANZANO, 259-320.

2012b Exposición de cadáveres en el yacimiento de Tordillos (Aldeaseca de la Frontera, Salamanca). Perspectiva bioarqueológica y posibles implicaciones para el estudio del ritual funerario de Cogotas I. Zephyrus 69, 95-128.

\section{ETXEBERRIA, F}

2003 Patología traumática. Paleopatología, en A. ISIDRO \& A. MALGOSA (Eds.), La Enfermedad no escrita. 195204. Masson. Barcelona.

FABIÁN GARCÍA, J.F. \& BLANCO GONZÁLEZ, A,

2012 Cuatro enterramientos calcolíticos en hoyo del Cerro de la Cabeza (Ávila). Complutum 23(1), 99-120.
FAUX, J.L.

2012. Hail the Conquering Gods: Ritual Sacrifice of Children in Inca Society. Journal of Contemporary Anthropology, 3.1, art. 1. Disponible en: http://docs.lib.purdue.edu/ jca/vol3/iss $1 / 1$

FERLLINI, R.,

2012 Macroscopic and Microscopic Analysis of Knife Stab Wounds on Fleshed and Clothed Ribs. Journal of FOrensic Sciences 57(3), 683-690.

\section{FOUCAULT, M}

1975 Surveiller et punir: naissance de la prison. Gallimard. Paris.

GAITHER, C.,

2012 Cultural conflict and the impact on non-adults at Puruchuco-Huaquerones in Peru: The case for refinement of the methods used to analyze violence against children in the archeological record. International Journal of Paleopathology 2.2-3, 69-77.

\section{GAITHER, C. \& MURPHY, M.}

2011 Consequences of conquest? The analysis and interpretation of subadult trauma at Puruchuco-Huaquerones, Peru. Journal of Archaeological Science 39(2), $467-$ 478. http://dx.doi.org/10.1016/j.jas.2011.10.002

\section{GARCÍA BARRIOS, A.}

2007 Un enfoque de género en la arqueología de la prehistoria reciente del valle medio del Duero: los cráneos femeninos calcolíticos de Los Cercados (Mucientes, Valladolid)", en ROSA, C. de la, DUEÑAS, M. J., VAL, M. I. del \& SANTO TOMÁS, M. (coords.). Nuevos enfoques para la enseñanza de la historia. Mujer y género ante el Espacio Europeo de Educación Superior. 41-56. Madrid. Asociación Cultural Al-Mudayna.

\section{GONZÁLEZ MARTÍN, A.}

2008 Mitos y realidades en torno a la excavación, el tratamiento y el estudio de los restos subadultos, en GUSI et al. 57-76.

GRAMSCH, A. \& MEIER, T.

2013 An Archaeological Outline of Ritual Dynamics and Social Space, en BERGERBRANT, S., \& SABATINI, S. (Eds.). Counterpoint. Essays in Archaeology and Heritage Studies in Honour of Professor Kristian Kristiansen. 193-198. Archaeopress. Oxford [BAR Int. S. 2508].

\section{GREEN, M}

1998 Humans as Ritual Victims in the Later Prehistory of Western Europe. Oxford Journal of Archaeology 17(2), 169-189.

GREEN, N. \& SWIONTKOWSKI, M. (Eds.).

2003 Skeletal trauma in children. Saunders - Elsevier Science. Philadelphia.

GUILAINE, J. \& ZAMMIT, J.

2001 Le sentier de la guerre: visages de la violence préhistorique. Seuil. Paris. 
GUSI, F., MURIEL, S. \& OLÀRIA, C. (Coords.)

2008 Nasciturus: Infans, Puerulus. Vobis Mater Terra. La muerte en la infancia. Servei d'Investigacions Arqueològiques i Prehistòriques. Castelló.

\section{HANDLER, J. S.}

1996 A Prone Burial from a Plantation Slave Cemetery in Barbados, West Indies: Possible Evidence for an African-type Witch or Other Negatively Viewed Person. Historical Archaeology 30(3), 76-86.

HARRIS, N.J. \& TAYLES, N.

2012 Burial containers. A hidden aspect of mortuary practices: Archaeothanatology at Ban Non Wat, Thailand. Journal of Anthropological Archaeology 31, 227-239.

HART, G.

2005 Fracture pattern interpretation in the skull: Differentiating blunt force from ballistic trauma using concentric fractures. Journal of Forensic Sciences 50(6), 1-6.

HUGHES, D. D.

1991 Human sacrifice in ancient Greece. Routledge, London.

HUMPHREY, J. \& HUTCHINSON, D.

2001 Macroscopic characteristics of hacking trauma. Journal of Forensic Sciences 46(2), 228-233.

JACKES, $M$.

2004 Osteological evidence for Mesolithic \& Neolithic violence: problems of interpretation, en ROKSANDIC, M. (ed.) Evidence \& meaning of Mesolithic violence. 23-39. Archaeopress, Oxford (BAR International Series 1237).

\section{JEUNESSE, C}

2010. Les sépultures en fosses circulaires de l'horizon 45003500. Contribution à l'étude comparée des systèmes funéraires du Néolithique européen, en: BARAY \& BOULESTIN. 28-48.

JIMÉNEZ-BROBEIL, S., AL OUMAOUI, I. \& DU SOUICH, Ph.,

2007 Childhood trauma in several populations from the lberian Peninsula. International Journal of Osteoarchaeo$\log 17,189-198$.

JIMÉNEZ-BROBEIL, S., ROCA, M.G., LAFFRANCHI, Z., NÁJERA, T. \& MOLINA, F.

2014 Violence in the Central Iberian Peninsula during the Bronze Age: A Possible Prehistoric Homicide. International Journal of Osteoarchaeology 24(5), 557-674.

JIMÉNEZ-BROBEIL, S.A., SOUICH, Ph. \& AL OUMAOUI, I.

2009 Possible relationship of cranial traumatic injuries with violence in the South-East Iberian Peninsula from the Neolithic to the Bronze Age", American Journal of Physical Anthropology 140, 465-475.
JOHNSTONE, E. W. \& FOSTER, B. K

2001 The biologic aspects of children's fractures, en BEATY, J., ROCKWOOD, C. \& KASER, J. (Eds.). Fractures in children. 21-47. Philadelphia: Williams \& Wilkins, Lippincott, $\left(5^{\text {th }}\right.$ ed.).

JUDD, M

2008 The parry problem. Journal of Archaeological Science 35, 1658-1666.

JURMAIN, R. \& BELLIFEMINE, V. I.

1997 Patterns of cranial trauma in a prehistoric population from central California. International Journal of Osteoarchaeology $7(1), 43-50$.

KANZ, F. \& GROSSCHMIDT, K.

2006 Head injuries of roman gladiators. Forensic Science International 160, 207-216.

KLEPINGER, L.

2006 Fundamentals of forensic anthropology. Wiley-Liss, Hoboken.

KEYS, D.

2004 The Executioner's Moat. Archaeology 57(2), 12.

KIMMERLE, E. \& BARAYBAR, J.

2008 Skeletal trauma. Identification of injuries resulting from human rights abuse \& armed conflict. CRC Press. Boca Raton.

KNÜSEL, C

2005 The physical evidence of warfare-subtle stigmata?, en PARKER PEARSON \& THORPE. 49-65.

KRENZER, U.

2006 Compendio de métodos antropológico forenses. Centro de Análisis Forense y Ciencias Aplicadas. Guatemala.

LARSEN, C. S.

1997 Bioarchaeology: interpreting behavior from the human skeleton. Cambridge University Press. Cambridge.

LECLERC, J.

1990 La notion de sépulture. Bulletin et Mémoires de la Société d'Anthropologie de Paris 2(3-4), 13-18.

LESSA, A. \& MENDONÇA DE SOUZA, S.

2004 Violence in the Atacama Desert during the Tiwanaku period: social tension?. International Journal of Osteoarchaeology 14(5), 374-388.

LEWIS, M

2007 The bioarchaeology of children. Perspectives from biological \& forensic anthropology. Cambridge University Press, Cambridge.

2008 Identifying sword marks on bone: criteria for distinguishing between cut marks made by different classes of bladed weapons. Journal of Archaeological Science $35,2001-2008$ 
LIESAU, C., RÍOS, P., BLASCO, C. \& GÓMEZ, J.L.

2014 Indicios de violencia en yacimientos de la región de Madrid en el marco del Calcolítico Peninsular. Gladius XXXIV, 7-36.

LILLIOS, K.T., (ed.)

2011 Comparative Archaeologies: The American Southwest (AD 900-1600) and the Iberian Peninsula (3000-1500 $B C)$. Oxbow Books: Oxford.

LITTLE, L. M. \& PAPADOPOULOS, J.K.

1998 A Social Outcast in Early Iron Age Athens. Hesperia 67(4), 375-404.

LOVELL, N.

1997 Trauma analysis in Paleopathology. Yearbook of Physical Anthropology 40, 139-170.

LOVELL, N. C.

2008 Analysis and interpretation of skeletal trauma, en KATZENBERG, M.A. \& SAUNDERS, S.R. (Eds.). Biological anthropology of the human skeleton. 341-386. Wiley-Liss. New York.

LUCERO, L.\& GIBBS, S.

2007 The Creation and Sacrifice of Witches in Classic Maya Society, en TIESLER \& CUCINA. 45-73.

LULL, V. \& RISCH, R

1995 El estado argárico. Verdolay 7, 97-109.

MARTIN, D. L. \& ANDERSON, C. P. (Eds.)

2014 Bioarchaeological and Forensic Perspectives on Violence. How Violent Death is Interpreted from Skeletal Remains. Cambridge University Press. Cambridge.

MAYS, S.

1998 The archaeology of human bones. Routledge. London-New York.

MIGUEL IBÁÑEZ, M.P. DE, UNZU URMENETA, M., FARO CARBALLA, J. A., PRIETO SÁEZ DE TEJADA, P. \& GARCÍA-BARBERENA UNZU, $M$

2008 Evidencias de ajusticiamiento: a propósito de una fosa común de época romana (s. II-IV) (Plaza del Castillo, Pamplona, Navarra), en ROCA DE TOGORES MUÑOZ, C. \& RODES LLORET, F. (eds.). Actas de las Jornadas de Antropología Física y Forense. 81-88. Instituto Alicantino de Cultura. Alicante.

MILELLA, M., MARIOTTI, V., BELCASTRO, M.G. \& KNÜSEL, C.J.

2015 Patterns of Irregular Burials in Western Europe (1st5th Century A.D.). PLOS ONE 10(6): e0130616. doi:10.1371/journal.pone.0130616.

MURPHY, E.M. (Ed.)

2008 Deviant Burial in the Archaeological Record. Oxbow Books, Oxford.
MYBURGH, A C

1974 Law and Justice, en HAMMOND-TOOKE, W. D. (Ed.) The Bantu-Speaking Peoples of Southern Africa. 264317. Routledge \& Kegan Paul. London.

NÁJERA, T., MOLINA GONZÁLEZ, F., JIMÉNEZ BROBEIL, S.A. AL OUMAQUI, I., ROCA, M ${ }^{2}$ G., HARO NAVARRO, M. \& FERNÁNDEZ MARTÍN, S.

2010 Un ejemplo de violencia interpersonal extrema durante la Edad del Bronce el enterramiento 60 de La Motilla del Azuer. Cuadernos de Prehistoria y Arqueología de la Universidad de Granada 20, 381-394.

O'CALLAGHAN, P., JONES, M., JAMES, D., LEADBEATTER, S. HOLT, C. \& NOKES, L.

1999 Dynamics of stab wounds: force required for penetration of various cadaveric human tissues. Forensic Science International 104, 173-178.

OGILVIE, M.D. \& HILTON, C.E.

2000 Ritualized Violence in the Prehistoric American Southwest. International Journal of Osteoarchaeology 10 $27-48$.

\section{OLIVER FOIX, A}

2004 Sacrificios y "mala muerte" en el Registro Arqueológico de los Yacimientos Ibéricos. Espacio, Tiempo y Forma, Serie I, Prehistoria y Arqueología 16-17, 391-417.

OTTO, T., THRANE, H. \& VANDKILDE, H. (Eds.),

2006 Warfare and Society: Archaeological and Social Anthropological Perspectives. Aarhus University Press, Aarhus.

PALOMINO, A. L., NEGREDO GARCÍA, M. J. \& ABARQUERO MORAS, F. J.

1999 Cabañas, basureros y tumbas en el yacimiento de El Cerro La Horra (Burgos). A vueltas sobre el significado de un campo de hoyos en la Edad del Bronce de la Meseta. Numantia 7, 21-41.

\section{PALOMO DÍEZ, S}

2015 Caracterización genética de las poblaciones de las Edades del Cobre y del Bronce de la Submeseta Norte de la Península lbérica. Tesis doctoral defendida en la Facultad de Biología de la Universidad Complutense de Madrid.

PARKER PEARSON, M. \& THORPE, I.J.N. (Eds.)

2005 Warfare, violence \& slavery in Prehistory. Proceedings of a Prehistoric Society conference at Sheffield Unversity. Archaeopress. Oxford (BAR International Series 1373).

PAUKETAT, T. R

2009 Wars, Rumors of Wars, and the Production of Violence, en NIELSEN, A. \& WALKER, W. (Eds.) Warfare in Cultural Context: Practice, Agency and the Archaeology of Violence. 244-261. University of Arizona Press. Tucson.

PÉREZ, V. R.

2011 Rethinking Violence: Behavioral and Cultural Implications for Ancestral Pueblo Populations (AD 900-1300), en LILLIOS. 121-151. 
PÉREZ, V. R. \& WEISS-KREJCI, E.

2011 Bridging Bodies, en LILLIOS. 103-120.

\section{POLLARD, J.}

2001 The aesthetics of depositional practice. World Archaeology 33(2), 315-333.

RALPH, S. (Ed.)

2013 The Archaeology of Violence. Interdisciplinary Approaches. SUNY Press. Albany.

REIMER, P. J., BARD, E., BAYLISS, A., BECK, J.W., BLACKWELL, P.G., BRONK RAMSEY, C. \& VAN DER PLICHT, J.

2013 IntCal13 and Marine13 Radiocarbon Age Calibration Curves 0-50,000 Years cal BP. Radiocarbon 55(4), 1869-1887.

REYNOLDS, A.

2009 Anglo-Saxon Deviant Burial Customs. Oxford University Press. Oxford.

\section{ROBERTS, C.}

2000 Trauma in biocultural perspective: past, present and future work in Britain, en COX \& MAYS. 337-356.

\section{ROBERTS, C. \& MANCHESTER, K.}

2007 The Archaeology of disease. Cornell University Press. Ithaca.

ROKSANDIC, M., DJURIĆ, M., RAKOČEVIĆ, Z. \& SEGUIN, K.

2006 Interpersonal violence at Lepenski Vir Mesolithic/Neolithic complex of the Iron Gates Gorge (Serbia-Romania). American Journal of Physical Anthropology 129 (3), 339-348.

RODRÍGUEZ MARCOS, J. A. \& FERNÁNDEZ MANZANO, J. (Eds.)

2012 Cogotas I. Una cultura de la Edad del Bronce en la Península Ibérica. Universidad de Valladolid, Valladolid.

RODRÍGUEZ MARCOS, J. A. \& MORAL DEL HOYO, S.

2007 Algunos ejemplos de ingeniería prehistórica poco conocidos: tres poblados amurallados del Bronce medio de la sub-Meseta norte, en Actas del Quinto Congreso Nacional de Historia de la Construcción. 775-780. CEHOPU. Madrid.

\section{SÁNCHEZ-POLO, A. \& BLANCO-GONZÁLEZ, A.}

2014 Death, relics, and the demise of huts: Patterns of planned abandonment in Middle Bronze Age Central Iberia. European Journal of Archaeology 17(1),4-26.

\section{SANTOS-GRANERO, F.}

2004 The Enemy Within: Child Sorcery, Revolution, \& the EviIs of Modernization in Eastern Peru, en WHITEHEAD, N. WRIGHT, R. (Eds.). Darkness \& Secrecy: the Anthropology of Assault Sorcery and Witchcraft in Amazonia. 272-305. Duke University Press. Durham.
SAUER, N.J.

1998 The timing of injuries and manner of death: distinguishing among antemortem, perimortem \& postmortem trauma, en REICHS, K.J.' (Ed.) Forensic Osteology. 321-332. Charles Thomas Publisher. Springfield.

SCHEUER, L. \& BLACK, S.

2000 Developmental juvenile osteology. Elsevier Academic Press. London.

SCHMIDT-SCHULTZ, T., SCHULTZ, M., SADORI, L., PALMIERI, A., MORBIDELLI, P., HAUPTMANN, A, DI NOCERA, G.M., \& FRANGIPANE, $M$.

2001 New Symbols of a New Power in a Royal Tomb from 3000 BC Arslantepe, Malatya (Turkey). Paléorient 27(2). 105-139.

SCHMITT, B. E. \& SCHRÖDER, I. W. (Eds.)

2001 Anthropology of Violence and Conflict. Routledge. London.

SCHWARTZ, H. \& HOLT, G.

2003 Pathologic fractures in children, en GREEN \& SWIONTKOWSKI. 63-79.

\section{SELLIER, P.}

1995 Paléodémographie et archéologie funéraire: les cimetières de Mehrgarh, Pakistan. Paléorient 21(2), 123-143.

SHAW, K., CHUNG, J., CHUNG, F., TSENG, B., PAN, C., YANG, K. \& YANG, C.

2011 A Method for Studying Knife Tool Marks on Bone. Journal of Forensic Sciences 56(4), 967-971.

SHAY, T.

1985 Differentiated Treatment of Deviancy at Death as Revealed in Anthropological and Archaeological Material. Journal of Anthropological Archaeology 4(3), 221-241.

SHKRUM, M. \& RAMSAY, D.

2007 Forensic pathology of trauma. Common problems for the pathologist. Humana Press. Totowa.

SORIANO, I., GIBAJA, J.F. \& VILA, LI.

2015 Open Warfare or the Odd Skirmish? Bell Beaker Violence in the Northeastern Iberian Peninsula. Oxford Journal of Archaeology 34(2), 157-183.

STEWART, P. J. \& STRATHERN, A.

2004 Witchcraft, sorcery, rumors and gossip. Cambridge University Press. Cambridge.

SYMES, S., ERICKA, N., L'ABBÉ, E. N., CHAPMAN, I. \& DIRKMAAT, D. C.

2012 Interpreting Traumatic Injury to Bone in Medicolegal Investigations, en DIRKMAAT, D.C. (Ed.). A Companion to Forensic Anthropology. 340-389. Willey-Blackwell. Chichestar.

TA'ALA, S., BERG, M. \& HADEN, K.

2006 Blunt force trauma in the Cambodian killing fields. Journal of Forensic Sciences 51(5), 996-1001. 
TARLOW, S.

2011 Ritual, Belief and the Dead in Early Modern Britain and Ireland. Cambridge University Press. Cambridge.

TESTART, A.

2004 Les morts d'accompagnement. 1, La servitude volontaire. Errance. Paris.

TESTART, A., JEUNESSE, C., BARAY, L. \& BOULESTIN, B.

2010 Les esclaves des tombes néolithiques. Pour la Science 396 (october), 74-80.

THOMPSON, T. \& INGLIS, J.

2009 Differentiation of serrated and non-serrated blades from stab marks in bone. International Journal of Legal Medicine 123, 129-135.

THORPE, I.

2003 Anthropology, archaeology and the origin of warfare. World Archaeology 35, 145-165.

TIESLER, $V$

2007 Funerary or Nonfunerary? New references in identifying ancient Maya sacrificial and postsacrificial behaviours from human assemblages, en TIESLER \& CUCINA. 14-44.

TIESLER, V. \& CUCINA, A. (Eds.)

2007 New perspectives on human sacrifice and ritual body treatments in ancient Maya society. Springer. New York.

TSALIKI, A.

2008 Unusual Burials \& Necrophobia: an Insight into the Burial Archaeology of Fear, en MURPHY. 1-16.

TUNG, T. \& KNUDSON, K.

2010 Childhood lost: Abductions, Sacrifice, and Trophy Heads of Children in the Wari Empire of the ancient Andes. Latin American Antiquity 21(1), 44-66.

\section{VAN HAEPEREN, F.}

2004 Sacrifices humains et mises à mort rituelles à Rome quelques observations. Folia Electronica Classica, 8 Disponible en: [http://bcs.fltr.ucl.ac.be/FE/08/sacrifices.htm, accesed November 2014].

VEGAS, J.I., ARMENDARIZ, A., ETXEBERRIA, F., FERNÁNDEZ, M.S. HERRASTI, L. \& ZUMALABE, F.

1999 La sepultura colectiva de San Juan ante Portam Latinam (Laguardia, Alava), en BERNABEU AUBAN, J. \& OROZCO KOHLER, T. (Eds.). Actes del I/ Congrès del Neolític a la Península Ibèrica. 439-445. Universitat de Valencia. Valencia [Saguntum-PLAV, Extra 2]

VEGAS, J. I., ARMENDARIZ, A., ETXEBERRIA, F., FERNÁNDEZ, M.S. \& HERRASTI, L.

2012 Prehistoric violence in northern Spain: San Juan ante Portam Latinam, en SCHULTING, R. J. \& FIBIGER, L. (Eds.). Sticks, Stones, and Broken Bones. Neolithic Violence in a European Perspective. 265-301. Oxford. Oxford University Press.
VILLES, A.

1986 Une hypothèse : les sépultures de relégation dans les fosses d'habitat protohistorique en France septentrionale, en DUDAY, H. \& MASSET, C. (Eds). Anthropologie physique et archéologie: méthodes d'étude des sépultures: actes du colloque de Toulouse, 4, 5 et 6 novembre 1982. 167-172. CNRS. Paris.

WALDRON, T.

2009 Palaeopathology. Cambridge University Press. Cambridge.

WALKER, P., COLLINS, D. \& LAMBERT, P.

1997 Skeletal Evidence for Child Abuse: A Physical Anthropological Perspective. Journal of Forensic Sciences 42(2), 196-207.

WILBER, J. \& THOMPSON, G.

2003 The Multiply Injured Child, en GREEN \& SWIONTKOWSKI. 81-117.

WILLIAMSON, M., JOHNSTON, C., SYMES, S. \& SCHULTZ, J.

2003 Interpersonal violence between 18th century native Americans \& Europeans in Ohio. American Journal of Physical Anthropology 122, 113-122.

WILSON, A.S., TAYLOR, T., CERUTI, M.C., CHAVEZ, J.A., REINHARD, J., GRIMES, V., MEIER-AUGENSTEIN, W., CARTMELL, L., STERN, B., RICHARDS, M.P., WOROBEY, M., BARNES, I., THOMAS, M. \& GILBERT, P.,

2007 Stable isotope and DNA evidence for ritual sequences in Inca child sacrifice. Proceedings of the National Academy of Sciences of the United States of America 104(42), 16456-1646. 